\title{
Progress of Aircraft System Noise Assessment with Uncertainty Quantification for the Environmentally Responsible Aviation Project
}

\author{
Russell H. Thomas ${ }^{1}$, Casey L. Burley ${ }^{2}$ \\ NASA Langley Research Center, Hampton, VA 23681 USA \\ And \\ Yueping $\mathrm{Guo}^{3}$ \\ NEAT Consulting \\ Seal Beach, CA 90740 USA
}

\begin{abstract}
Aircraft system noise predictions have been performed for NASA modeled hybrid wing body aircraft advanced concepts with 2025 entry-into-service technology assumptions. The system noise predictions developed over a period from 2009 to 2016 as a result of improved modeling of the aircraft concepts, design changes, technology development, flight path modeling, and the use of extensive integrated system level experimental data. In addition, the system noise prediction models and process have been improved in many ways. An additional process is developed here for quantifying the uncertainty with a $95 \%$ confidence level. This uncertainty applies only to the aircraft system noise prediction process. For three points in time during this period, the vehicle designs, technologies, and noise prediction process are documented. For each of the three predictions, and with the information available at each of those points in time, the uncertainty is quantified using the direct Monte Carlo method with 10,000 simulations. For the prediction of cumulative noise of an advanced aircraft at the conceptual level of design, the total uncertainty band has been reduced from 12.2 to 9.6 EPNL dB. A value of 3.6 EPNL $\mathrm{dB}$ is proposed as the lower limit of uncertainty possible for the cumulative system noise prediction of an advanced aircraft concept.
\end{abstract}

\section{Introduction}

$\mathrm{T}$ he NASA Environmentally Responsible Aviation (ERA) Project has focused on developing and demonstrating technologies for integrated aircraft systems that could meet simultaneously aggressive goals for fuel burn, noise, and emissions [1]. The fuel burn goal is for a reduction of $50 \%$ relative to a bestin-class 2005 aircraft; the noise goal is 42 EPNL dB (Effective Perceived Noise Level) cumulative below the Stage 4 requirement; and the emissions goal is for a reduction of $75 \%$ in NOx (oxides of nitrogen) levels below the CAEP 6 (Committee on Aviation Environmental Protection) standard. The target date is 2020 for key technologies to be at a technology readiness level (TRL) of 4-6 (system or sub-system prototype demonstrated in a relevant environment). This timeline corresponds to a projected aircraft entry into service by 2025 . These goals with the timeframe are defined by NASA with the term $\mathrm{N}+2$, where $\mathrm{N}$ represents the current generation of aircraft technology in service today, and $\mathrm{N}+2$ technology would be expected to be implemented in aircraft two product cycles from now. As are all the $\mathrm{N}+2$ goal levels, the noise goal was intended as a significant technical challenge. Through the early research leading up to determining the goal level, it was thought that a configuration change would likely be necessary to enable achieving a significant noise reduction goal representing a step change in aircraft noise [2]. Thomas et al. [3] includes a description of the NASA research during 2003-2007 that resulted in the calculation of 42 EPNL $\mathrm{dB}$, based on several significant assumptions, as the potential low noise level achievable with a Hybrid

\footnotetext{
${ }^{1}$ Senior Research Engineer, Aeroacoustics Branch, MS 461, AIAA Senior Member

${ }^{2}$ Senior Research Engineer, Aeroacoustics Branch, MS 461, AIAA Senior Member

${ }^{3}$ NEAT Consulting, 3830 Daisy Circle, Seal Beach, CA 90740, AIAA Associate Fellow
} 
Wing Body (HWB) aircraft concept. The study of Thomas et al. [3] and Czech et al. [4] became the first in a series of studies [5-7] during ERA to develop the HWB aircraft configuration including propulsion airframe integration, noise reduction technology, and the process by which higher fidelity noise assessments could be made with increasing confidence. This first ERA noise study [3 and 4] used the best NASA model in 2009 of a 300 passenger HWB with GE90-like engines. The combined experimental noise reduction technology and assessment study was focused on determining a technical strategy (including identification of the noise benefits of enabling technologies) to reach the noise goal and on acquiring the best available high quality data for shielding effects at the time [4]. Thomas and Burley [8] reported in 2009 the initial assessment result of 41.1 EPNL dB cumulative below the Stage 4 limit. Rigorous recalculation with exactly the same assessment information for subsequent publication in 2012 showed the final result to be 42.9 EPNL dB [3]. Since that time, two additional changes have been made to the final cumulative number. First, the correct weight was used to calculate the certification limit on approach and second, based on new knowledge [6] the landing gear noise was recalculated with the improved local velocity. As a result, the published assessment process in 2012 [3] will be used to represent the status of the noise assessment at the beginning of ERA in 2009, but the cumulative value for that 2009 study will be reported here as the corrected value of 42.4 EPNL dB cumulative below the Stage 4 limit.

During the final three years of ERA, 2013-2016, annual aircraft system level noise assessments have been conducted on a portfolio of aircraft concepts to demonstrate by analysis the performance of the integrated advanced vehicles and technologies compared to the original ERA N+2 goals. The aircraft concepts include a full range of technology assumptions deemed feasible for the 2025 timeframe and have incorporated the results of a series of experimental results produced by ERA projects with industry partners throughout the six years of ERA to advance the maturation of key technologies. Each annual assessment included refined aircraft models and new experimental inputs based on progress to date. Nickol and Haller [9] describe the modeling of the aircraft in detail and the fuel burn and emissions reduction assessment results at the conclusion of ERA in 2016. The 2013 assessment included an earlier iteration of the NASA HWB aircraft including GTF-like engines (geared ultra high bypass ratio turbofans). Compared to the original study [3], the technologies and vehicle definition were more advanced and comprehensive by including the GTF engines, laminar flow drag reduction, and lighter weight structures among other technologies.

The 2013 ERA noise assessment relied entirely on prediction of the GTF-like engine source levels and ranking of sources. The assessed level of the HWB with GTF engines in this 301-passenger class was 49.2 EPNL dB below Stage 4. Thomas et al. [10] describes the final acoustic prediction method and resulting noise assessment results achieved at the conclusion of ERA. In these final ERA noise assessment results, the Hybrid Wing Body (HWB) aircraft with GTF engines reached a noise level of 40.2 EPNL dB cumulative below Stage 4 after an additional iteration compared to the results presented in [9 and 10].

The purpose of this paper is to describe the progression from that first ERA noise assessment study in 2009 , to the intermediate assessment in 2013, and then to the final study in early 2016. These three dates will be used in describing the progression of the ERA noise assessment through the six years of ERA. This description of the progression will include the vehicle technology, noise reduction approaches and the noise assessment prediction methodology. And finally, an uncertainty quantification process for aircraft system noise prediction will be proposed and applied to the ERA assessment results as they were calculated in 2009,2013 , and finally in 2016. The uncertainty calculated is that of the acoustic prediction only and not associated with the vehicle design. The progression of the uncertainty quantification results through ERA will be reported.

\section{Progression of Hybrid Wing Body Aircraft Concepts}

The HWB aircraft in the Large Twin Aisle (LTA) class, 301 passenger size, shall be the focus of this paper. During ERA, the HWB was designed for a 7500 nautical mile mission equivalent to a NASA model of the 777-200LR-like reference aircraft, including payload, range and reserve mission requirements. The NASA design and predicted performance of the HWB concept aircraft has developed over time based on improved models and test results obtained throughout the duration of ERA including information from industry partners. An overview of the HWB vehicle model results and performance used in this study is shown in Table 1 for the NASA models of the HWB in 2009, 2013, and 2016.

For the 2009 study, the Aeronautical Systems Analysis Branch of NASA Langley and the Propulsion Systems Analysis Branch of NASA Glenn Research Center modeled the HWB300 vehicle and the GE-90- 
like engine, respectively. Nickol and McCullers [11] describe the development of the HWB300 concept. The HWB300 instead uses an equivalent mission of the 777-200ER (with GE90-85B engines) reference aircraft, including payload, range and reserve mission requirements. The planform is based on the Boeing BWB-450 aircraft, but is scaled down to maintain consistency with the smaller payload of the HWB300.

Table 1. Summary of ERA HWB Vehicle Models and Performance Metrics.

\begin{tabular}{|c|c|c|c|c|}
\hline & Units & $\begin{array}{l}\text { HWB300-GE90- } \\
\text { like 2009 }\end{array}$ & $\begin{array}{c}\text { HWB301-GTF } \\
2013 \\
\end{array}$ & $\begin{array}{c}\text { HWB301-GTF } \\
2016 \\
\end{array}$ \\
\hline $\begin{array}{l}\text { Abbreviated } \\
\text { Nomenclature }\end{array}$ & & HWB-2009 & HWB-2013 & HWB-2016 \\
\hline Entry Into Service & & 2020 & 2025 & 2025 \\
\hline Takeoff Gross Weight & $\mathrm{lb}$ & 590,436 & 558,760 & 535,164 \\
\hline $\begin{array}{l}\text { Operating Empty } \\
\text { weight }\end{array}$ & $\mathrm{lb}$ & 299,610 & 260,843 & 253,806 \\
\hline Payload & $\mathrm{lb}$ & 63,745 & 118,100 & 118,100 \\
\hline Passengers & & 300 & 301 & 301 \\
\hline Range & $\mathrm{Nm}$ & 7500 & 7500 & 7500 \\
\hline Total Fuel & $\mathrm{lb}$ & 227,081 & 179,817 & 163,258 \\
\hline Cruise Mach & & 0.84 & 0.84 & 0.84 \\
\hline Start of Cruise $L / D$ & & 23.0 & 23.0 & 23.7 \\
\hline Number of Engines & & 2 & 2 & 2 \\
\hline $\begin{array}{l}\text { Thrust per Engine (sea } \\
\text { level static) }\end{array}$ & $\mathrm{lb}$ & 81,298 & 72,842 & 70,124 \\
\hline Fan Diameter & inches & 118.8 & 126.4 & 132.4 \\
\hline $\begin{array}{l}\text { Fan Pressure Ratio } \\
\text { (FPR) at Aerodynamic } \\
\text { Design Point (ADP) }\end{array}$ & & 1.57 & 1.375 & 1.35 \\
\hline Bypass Ratio at ADP & & 8.6 & 14.9 & 17.65 \\
\hline $\begin{array}{l}\text { Start of Cruise } \\
\text { Specific Fuel } \\
\text { Consumption }\end{array}$ & $\mathrm{lbm} / \mathrm{hr} / \mathrm{lbf}$ & 0.549 & 0.495 & 0.475 \\
\hline Throttle: Approach & $\begin{array}{l}\text { Full } \\
\text { throttle = } \\
1.0\end{array}$ & 0.129 & 0.08 & 0.124 \\
\hline Throttle: Sideline & & 1.0 & 1.0 & 1.0 \\
\hline Throttle: Cutback & & 0.76 & 0.85 & 0.60 \\
\hline Takeoff Field Length & $\mathrm{ft}$ & 8633 & 9968 & 8023 \\
\hline Approach Speed & Knots & 115 & 147.9 & 133.0 \\
\hline
\end{tabular}

The HWB300 aircraft developed by Nickol and McCullers [11] was assumed to have a technology level consistent with a 2020 entry-into-service date. One of the primary purposes of the 2009 noise assessment study was to examine the configuration-dependent propulsion airframe aeroacoustic (PAA) integration impacts of an HWB concept. At the time, there was a major gap in the prediction capability and, therefore, uncertainty of these PAA effects and noise reduction impacts. The 2009 study was framed to compare the HWB relative to the conventional configuration 777-200ER-like reference aircraft and, therefore, equivalent technology levels were required. The advanced engine was replaced with the same GE90-like engines as the NASA 777-200ER-like aircraft model, and other advanced technologies such as advanced composites, advanced high-pressure hydraulics, variable camber, hybrid laminar flow and embedded boundary-layer ingesting inlets were removed from the model to create an HWB concept with identical mission, payload and technology level. The HWB300 GE90-like engines were scaled to achieve a minimum gross weight while meeting the same takeoff field length as the 777-200ER and meeting all requirements for second-segment and missed-approach climb gradients, resulting in an aircraft with a gross weight of $590,436 \mathrm{lb}$ and sea-level static thrust of $81,298 \mathrm{lb}$ per engine. The modeled results for the HWB300 used in the 2009 noise assessment with GE90-like engines are listed in Table 1. As a result of the framework of the study, the 2009 HWB300-GE90-like vehicle model was not intended to represent a true 
$\mathrm{N}+2$ vehicle or technology level other than the advanced HWB configuration itself. The use of GE90-like engines provided an insightful modeling framework to be able to focus on the propulsion airframe aeroacoustic (PAA) integration impacts of an HWB and to also develop the high fidelity noise assessment process. This process would be necessary later for the noise assessment of the ERA N+2 HWB concepts, as well as other advanced concepts. This framework was necessary for the accurate quantification and assessment of the PAA effects for the HWB. In addition, the 2009 study supported the development of a technical roadmap for the noise reduction approach necessary to achieve the $\mathrm{N}+2$ noise goal. And finally, this study provided a specific technical roadmap that could have been used for a large-scale demonstrator test aircraft using off-the-shelf engines available during that time period.

Essential to the noise reduction approach of the HWB-2009 was the need to address the most significant noise sources. The engines were installed at a location upstream of the trailing edge of the HWB equivalent to two fan nozzle exit diameters and measured from the core nozzle exit plane to the trailing edge. This was done to provide significant noise reduction of aft-radiated engine noise sources; however, there was no aerodynamic analysis available at the time to guide this choice. Even with this location, the jet noise had to be reduced further because jet noise sources can be distributed many nozzle diameters downstream, depending on frequency. Based on extensive experimental study, the nozzle configuration of the HWB2009 included advanced PAA chevrons and a crown pylon that extended the upper bifurcator downstream of the fan exit nozzle. This configuration reduced low frequency jet noise while redistributing, both axially and azimuthally, the peak jet noise sources so that the shielding noise reduction from the airframe aft of the engine would be much greater. An advanced duct acoustic liner concept was applied to the upper bifurcator walls. The concept of an aggressive main landing gear fairing was included. And given the low speed aerodynamic data available at the time, the approach speed was lowered to 115 knots. More details and context on the framework of the HWB-2009 study and the noise specific technologies included in the concept are found in $[3,4$ and 6$]$.

During the final three years of ERA, the incorporation of N+2 technology and the modeling of the HWB advanced rapidly based on improved model development and industry partnership with NASA [1114]. As can be seen in Table 1, the performance of the HWB vehicles improved with the introduction of a full range of $\mathrm{N}+2$ technologies and as new results from research were incorporated over the final three years. These ERA vehicles were designed to simultaneously meet all three of the $\mathrm{N}+2$ goals. NASA tools were used for the vehicle and engine modeling including Flight Optimization System (FLOPS) [15], Modified Vortex Latice (MVL) [16], Numerical Propulsion System Simulation (NPSS) [17], and Weight Analysis of Gas Turbine Engines (WATE++) [18]. More details on how the tools were used for the ERA analysis are provided by Nickol and Haller [9].

The airframe technologies included a lighter weight structure enabled by damage arresting composites, natural laminar flow wing and nacelle, and smaller vertical tails due to active flow control enhancements. An advanced high lift system was modeled including a Krueger leading edge enabling a laminar flow wing by providing protection from insect and debris accretion. The ultra high bypass ratio geared turbofan (GTFlike) engine architecture included technologies such as a low pressure ratio fan with short inlet, swept and leaned fan exit stators, a highly loaded high-pressure compressor, which enabled higher overall pressure ratios, and a low NOx (oxides of nitrogen) combustor. In addition to the direct and indirect impact on vehicle noise of these technologies, a set of specific noise reduction technologies was also considered. These included a soft vane technology, an acoustic liner integral to the fan exit stator vane, and a partial noise reduction fairing for the main landing gear.

The HWB-2013 was the first in the series of annual modeling updates during the final half of ERA and used the best available information at the time of each update. At the conclusion of ERA, Nickol and Haller [9] describe the modeling process for the HWB and GTF-like engines. The HWB with GTF-like engines in 2016 was resized and updated from the NASA initial design iteration in 2013 and incorporated the latest experimental results from the final years of ERA. Significantly, the cruise condition aerodynamic analysis and vehicle design work now required the engine location to be set at one diameter upstream of the HWB trailing edge beginning with the HWB-2013 onward. For the HWB-2016, a nacelle diameter constraint had been imposed on the engine also reflecting analysis of the interference drag at cruise conditions. Compared to the HWB-2013, the HWB-2016 moved the vertical control surfaces from the wing tip to the in-board location on the centerbody. The low speed aerodynamic performance of the HWB-2016 was also updated based on wind tunnel experimental results [19 and 20]. This new information had direct impact on the rigging of the leading edge Krueger flap to seal the Krueger at both approach and takeoff conditions. Furthermore, the approach speed was updated. 
To summarize, Figure 1 shows the rendering of the quietest configuration from the HWB-2009 vehicle that was assessed at a margin of $42.4 \mathrm{~dB}$ below the Stage 4 limit. Figure 2 shows the rendering of the HWB-2013 vehicle that was assessed at 49.2 EPNL dB cumulative below the Stage 4 limit. And finally, Figure 3 shows the rendering of the HWB-2016 vehicle assessed at 40.2 EPNL dB cumulative below Stage 4. Table 1 has listed several of the design and performance parameters of each vehicle, all of which have an influence on the noise performance either directly or indirectly. Based on the brief discussion of each vehicle above, Tables 2 and 3 provide a summary of an additional number of important features, specific noise reduction technologies, or parameters that were included and that can be significant in understanding the noise assessment levels. However, for completeness it is important to note that not every parameter that can influence aircraft noise could be listed in this publication.

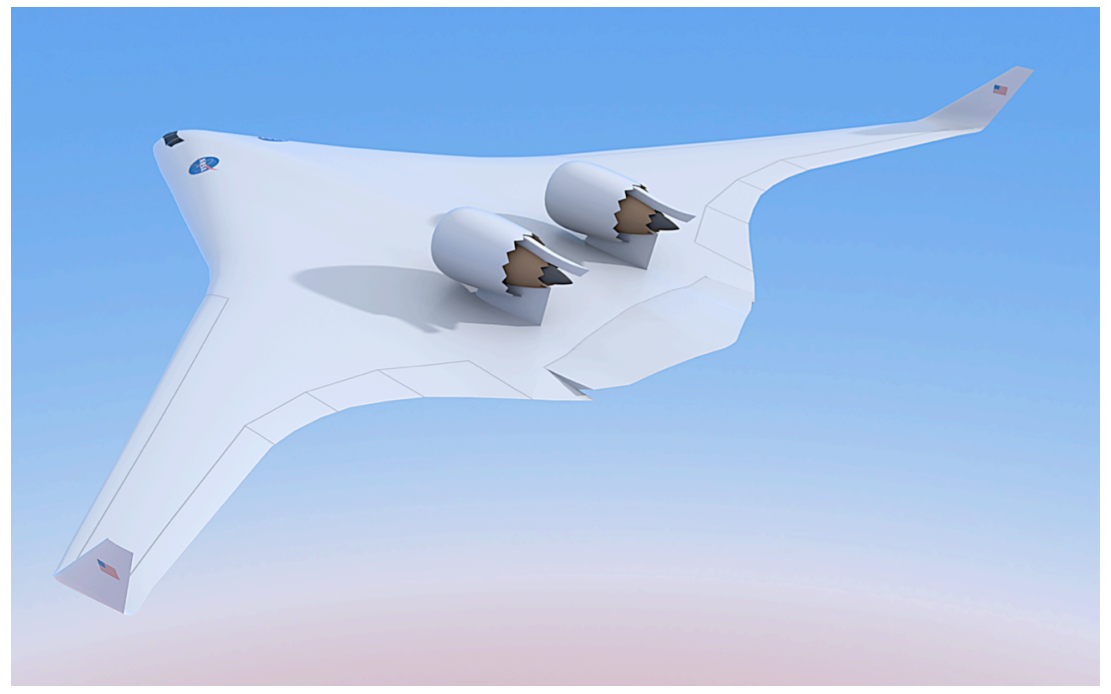

Figure 1. Rendering of the HWB300 with noise reduction design and technologies (from [3]).

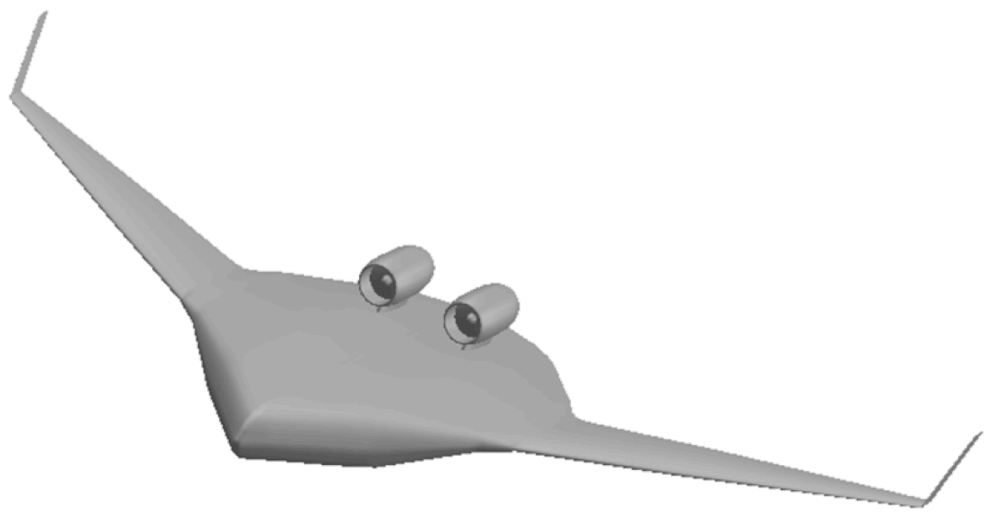

Figure 2. Rendering of the HWB-2013 with GTF-like engines and wing tip vertical control surfaces. 


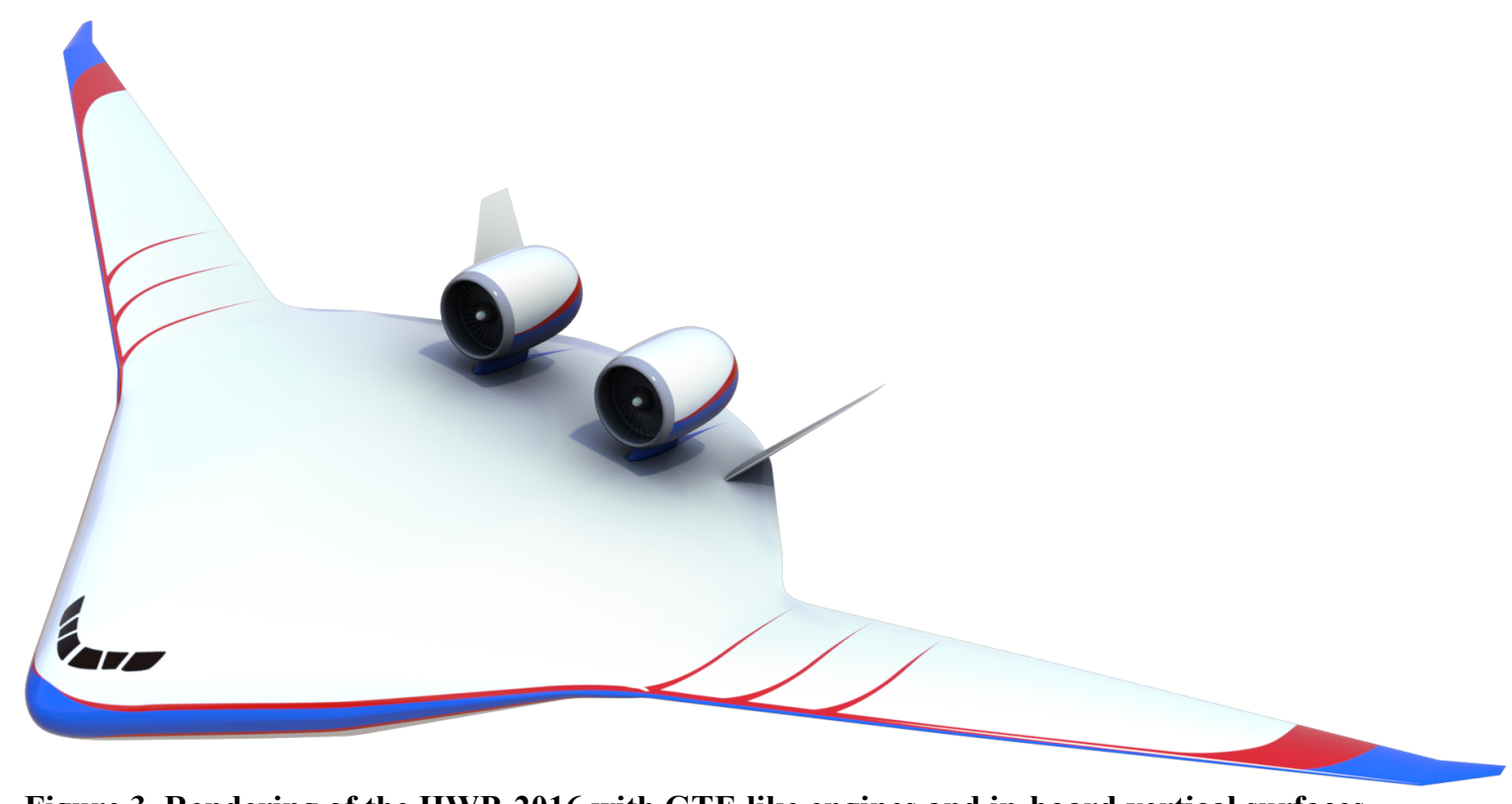

Figure 3. Rendering of the HWB-2016 with GTF-like engines and in-board vertical surfaces.

Table 2. Summary for all three studies of some key engine, propulsion airframe integration, and acoustic liner technologies and design parameters.

\begin{tabular}{|c|c|c|c|}
\hline & HWB-2009 & HWB-2013 & HWB-2016 \\
\hline $\begin{array}{l}\text { Engine location, core } \\
\text { nozzle exit plane to } \\
\text { trailing edge }(D=\text { fan } \\
\text { nozzle exit diameter) }\end{array}$ & $2 \mathrm{D}$ & $\begin{array}{l}\text { 1D for vehicle design } \\
\text { but } 2 \mathrm{D} \text { used in the } \\
\text { acoustic assessment }\end{array}$ & $1 \mathrm{D}$ \\
\hline $\begin{array}{l}\text { Jet noise reduction } \\
\text { technology }\end{array}$ & $\begin{array}{c}\text { PAA chevron and crown } \\
\text { pylon for BPR } 7\end{array}$ & $\begin{array}{c}\text { PAA chevron for higher } \\
\text { bypass ratio nozzle }\end{array}$ & $\begin{array}{l}\text { Conventional round } \\
\text { nozzle, no chevron }\end{array}$ \\
\hline $\begin{array}{l}\text { Acoustic duct liner } \\
\text { technology }\end{array}$ & $\begin{array}{c}\text { Assumed advanced duct } \\
\text { liner technology, } \\
\text { includes impact of } \\
\text { splices }\end{array}$ & $\begin{array}{c}\text { Double-degree of } \\
\text { freedom (DDOF) inlet, } \\
\text { Single-degree of } \\
\text { freedom (SDOF) aft } \\
\text { duct, includes impact of } \\
\text { splices } \\
\end{array}$ & $\begin{array}{l}\text { Multi-degree of freedom } \\
\text { (MDOF) inlet and aft } \\
\text { duct liner, spliceless }\end{array}$ \\
\hline $\begin{array}{l}\text { Inlet duct liner } \\
\text { effective length to } \\
\text { radius ratio }\end{array}$ & 0.77 & 0.78 & 0.67 \\
\hline $\begin{array}{l}\text { Aft duct liner effective } \\
\text { length to height ratio }\end{array}$ & 3.35 & 2.17 & 2.54 \\
\hline $\begin{array}{l}\text { Interstage liner } \\
\text { effective length to } \\
\text { height ratio }\end{array}$ & none & none & 0.25 \\
\hline $\begin{array}{l}\text { Additional liner } \\
\text { application/technology }\end{array}$ & $\begin{array}{c}\text { Application on the upper } \\
\text { bifurcator area }\end{array}$ & $\begin{array}{l}\text { Over-the-rotor treatment } \\
\text { with an assumed noise } \\
\text { reduction equal to } 1.0 \\
\text { EPNL dB at total engine } \\
\text { level }\end{array}$ & none \\
\hline $\begin{array}{l}\text { Soft stator vane } \\
\text { acoustic liner }\end{array}$ & none & $\begin{array}{c}\text { Assumed noise } \\
\text { reduction equal to } 1.5 \\
\text { EPNL dB at total engine } \\
\text { level }\end{array}$ & $\begin{array}{c}\text { Noise reduction from } \\
\text { data at the spectral level }\end{array}$ \\
\hline
\end{tabular}


Table 3. Summary of some key airframe technologies of the aircraft designs for all three studies.

\begin{tabular}{|l|c|c|c|}
\hline HWB-2009 & HWB-2013 & HWB-2016 \\
\hline $\begin{array}{l}\text { Leading edge device } \\
\text { type }\end{array}$ & Conventional slat & $\begin{array}{c}\text { Krueger with gap on } \\
\text { approach, sealed on } \\
\text { takeoff and flyover }\end{array}$ & $\begin{array}{c}\text { Krueger with sealed gap } \\
\text { on approach, takeoff, } \\
\text { and flyover }\end{array}$ \\
\hline Main landing gear type & 6 wheel, 777-like & 6 wheel, 777-like & 6 wheel, 777-like \\
\hline $\begin{array}{l}\text { Landing gear noise } \\
\text { reduction technology }\end{array}$ & $\begin{array}{c}\text { Assumed redesign of } \\
\text { gear with fairing to } \\
\text { achieve assumed 5 dB } \\
\text { reduction of component } \\
\text { spectra }\end{array}$ & $\begin{array}{c}\text { Partial main gear fairing } \\
\text { resulting in a 1.5 EPNL } \\
\text { dB component reduction }\end{array}$ & $\begin{array}{c}\text { Partial main gear } \\
\text { fairing, spectral level } \\
\text { data equal to about 2 } \\
\text { EPNL dB of component } \\
\text { noise reduction }\end{array}$ \\
\hline $\begin{array}{l}\text { Centerbody elevon } \\
\text { deflection for trim }\end{array}$ & Up 10 degrees & Up 10 degrees & Up 10 degrees \\
\hline
\end{tabular}

\section{Progression of the Noise Assessment Process}

The overall ERA noise assessment process has used a similar approach for predicting the noise of advanced and unconventional aircraft as was established in the first assessment for the HWB-2009 [3]. The ERA noise assessment process includes utilizing the best noise assessment practices, databases, and methods developed at NASA over the previous decades for predicting community noise. A key aspect of this process has been to directly predict the effects of the propulsion airframe aeroacoustic (PAA) integration with an experimental data-based process. In addition, during the course of ERA, the noise assessment process has been continuously updated through increasingly detailed aircraft definition, component modeling improvements, incorporation of the latest information from the Integrated Technology Demonstration (ITD) experiments, and through improved vehicle design and flight path iterations with the aircraft modeling and propulsion teams. This section will describe the cumulative noise metric calculation and then describe how the overall noise assessment process has progressed during ERA.

An overview chart for the cumulative noise metric is shown in Figure 4. Specifically, the noise metric for the 2025 aircraft models is certification community noise as defined in the Code of Federal Regulations (CFR) Title 14, Part 36. In order to obtain Federal Aviation Administration (FAA) certification, the noise of an aircraft must be below a defined level as measured according to the rules of Part 36. In the context of the research and technology maturation of integrated aircraft systems, the noise of ERA aircraft concept models is predicted according to the same Part 36 rules. Part 36 defines specific parameters for aircraft noise at each of three certification points. At each of the three certification points, the EPNL $\mathrm{dB}$ is predicted for the aircraft. Separate computations are performed to obtain each of the approach, lateral, and flyover EPNL noise levels. This procedure is consistent with previous assessments performed under NASA projects $[3,5-8$, and 10]. After calculation of the EPNL dB at each of the three certification points, the cumulative (CUM) noise is the addition of the EPNL of the three points. Furthermore, the cumulative noise is referenced relative to the certification level required by the FAA in Part 36; the current regulation is termed Stage 4 and is a function of aircraft weight and the number of engines. In sum, the cumulative noise below Stage 4 is the final noise metric reported by ERA. 


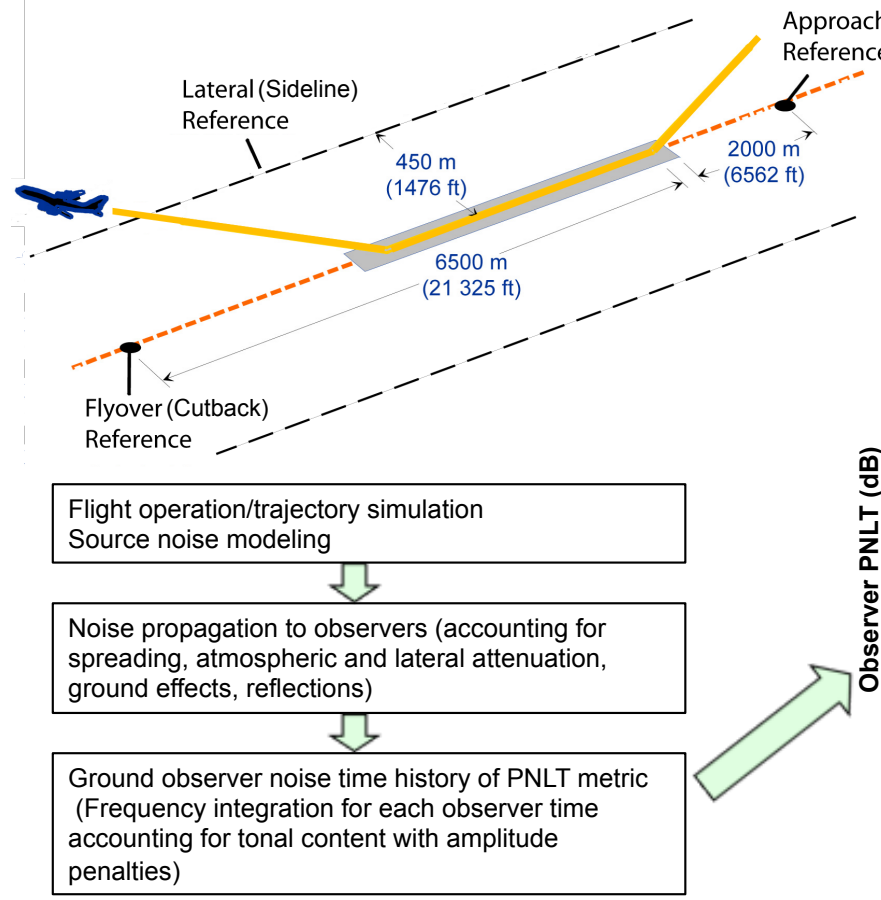
Noise certification points
- Lateral (Sideline)
- Flyover with Cutback
- Approach

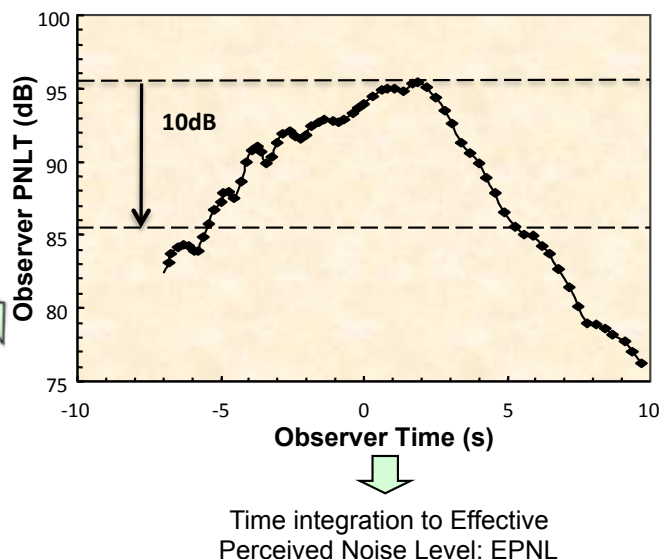

Figure 4. Noise certification flight paths and metric definitions used in the system noise assessment process. (Definitions guided by the Code of Federal Regulations (CFR) Title 14 Part 36)

\section{A. HWB-2009 Noise Assessment Process}

For the 2009 study, the first generation Aircraft NOise Prediction Program (ANOPP) was used, and the procedures, source models, and experimental information used are fully described in [3]. Figure 5 shows the overview of the process used. At the time that this study was formulated, it was deemed that a sufficient model of an ultra high bypass ratio geared type engine with associated engine source rank order (highest to lowest) and system noise prediction methods for these engine sources were insufficient or unavailable. Therefore, due to the importance of accurate engine source noise levels and ranking, this first study was setup to use the GE90-like engine. Typically, engine source noise is protected information by engine and aircraft manufacturers. Through years of assimilating GE90-like engine information (design, performance and noise data), a representative model of the engine cycle required for accurate noise source prediction was created for the study of [3]. The use of the GE90 engine noise information created high certainty for the engine noise levels and rank ordering and allowed the focus on the development of the data and technology for propulsion airframe aeroacoustic (PAA) interactions. The GE90 engine noise information together with noise certification information for the 777-200ER (reference aircraft for this study) was used in a multi-step process as described in [3] to establish the engine levels on the HWB-2009.

For the HWB, the PAA effects are a key to accurate system noise assessment. The HWB-2009 was the first assessment where high quality PAA data were available. The data used came from the PAA experiment in the Boeing Low Speed Aeroacoustics Facility (LSAF) documented in [4], and the data was applied in the form of suppression functions [3, 7 and 10]. For the jet noise, the PAA data are high fidelity and at the relevant conditions and, therefore, the suppression functions applied are of high fidelity. For internal engine noise sources, ANOPP predicts the source noise (fan and core) levels and directivity for both tones and broadband noise. However, the suppression applied is that obtained from the experimental data using a broadband point source. While a significant component of engine noise is broadband, the suppression of tones may be different due to, at least, directivity and interference. The experimental data do include the important effect of forward flight to the suppression function, an effect not available previously. As a result, the use of a suppression function for the broadband source is a good approximation and the best available at the time of this study.

A final step in the prediction process is to check the rank ordering of the engine sources and the 
airframe sources by cross referencing with known sources of information as described in [3 and 10]. Even with excellent component level predictions, the ranking of sources may not be sufficiently accurate due to many issues. Most likely possibilities are multiple simultaneous effects stemming from some combination of PAA effects, flight effects, and the impacts of full-scale, full-fidelity implementation. For the HWB2009 , the engine rank ordering was accomplished with the process described above. An initial experiment of the HWB airframe with a conventional slat had been performed [21]; however, the analysis was not available for the assessment, and the experiment did not have landing gear on the model. Therefore, the ranking of the slat and landing gear sources was based on judgment primarily from experience with conventional configurations.

The processes described in this section were keys to this study and will be used in Section IV. They will also be factors in the uncertainty quantification for the HWB-2009. The final result for HWB-2009 was reported as a cumulative noise reduction of 42.4 EPNL dB below the Stage 4 limit.

\section{B. HWB-2013 Noise Assessment Process}

For the intermediate HWB-2013 study, Figure 6 schematically shows the overview of the noise assessment process used. It is noted that the HWB-2013 noise result has not been reported previously. The noise assessment calculation was transitioned and was performed using the NASA multi-fidelity aeroacoustic framework known as the second generation Aircraft Noise Prediction Program (ANOPP2) [22]. The ANOPP2 framework allows a user to develop acoustic analyses and more easily couple results from these analyses with prediction methods and other data into a unified process. For ERA, analysis capabilities were developed to apply flight effects to the input measured source noise (which includes PAA effects), combine those measurements with legacy ANOPP predictions of other sources, propagate to the far field, and compute noise metrics.

As previously discussed, the HWB-2013 was the first full N+2 HWB model in ERA also using the GTF-like engines. Without experimental data for GTF-like specific engine noise sources at the time, this assessment relied on the best available legacy ANOPP prediction methods. These methods are semiempirical, and were not, in general, developed for GTF-like design parameters, particularly for the fan noise and core noise components. This was also true for the rank ordering of the engine noise sources for a geared design and for the much higher bypass ratios as compared to the prior experience base. For the fan noise source, the best method was the Kresja [23] model within the ANOPP-HDNFAN (Heidmann) prediction model. For the core noise, the GECOR method was used. No additional rank ordering of the engine sources was possible.

The airframe of the HWB-2013 now included a Krueger flap for the leading edge device as well as the six wheel, 777-like main landing gear. Both the prediction of the Krueger source as well as the rank ordering was a new challenge. The Krueger source noise was predicted using the BoeingSlat method developed for conventional slat leading edges with an estimated difference to account for the design and noise sources unique to the Krueger. The method for an estimated prediction of the Krueger source noise and for ranking the Krueger and main landing gear sources followed the experience provided by Yueping Guo [5, 6, 21, and 24].

For the key PAA effects, the same database from the LSAF experiment [4] was used again with the same engine installation location at 2 fan nozzle exit diameters (D) upstream of the HWB trailing edge. This was a temporary disconnect between the noise assessment of the HWB-2013 and the recently completed analysis by Boeing [5] that had established the engine installation at 0.94D (later at 1D) upstream of the trailing edge to better balance the goal of noise reduction with the aerodynamic challenges of installing the engine upstream of the trailing edge in the high Mach number region at cruise condition. Also of note is the fact that PAA datasets with several improved, higher fidelity features from LSAF [25] and from the N2A experiment in the 14- by 22-Foot Subsonic Tunnel [26 and 27] had been acquired but were not available to be included yet.

The final result of the HWB-2013 assessment was a cumulative noise margin of $49.2 \mathrm{EPNL}$ dB below the Stage 4 limit.

\section{HWB-2016 Noise Assessment Process}

The ERA noise assessment results were reported [10] in January, 2016, and also include a detailed description of the process used. The assessment reported here for the HWB-2016 includes several updates to both vehicle modeling as well as the noise assessment process as compared to that reported in [10]. The 
differences in vehicle modeling were primarily the result of incorporating the latest aerodynamic test results [19 and 20] that impacted the approach speed and the sealing of the Krueger flap on approach, as were mentioned in the discussion relative to Table 1.

For the assessment of [10], the new landing gear prediction method, Guo-LG [28], had been incorporated. For the HWB-2016 reported in this study, Guo-LG was also used. In addition the new GuoKrueger method [29] now replaced the prior method of estimating the Krueger flap source noise with the Boeing-Slat method. Based on the new improved landing gear and Krueger flap methods, Guo-LG and Guo-Krueger, the predicted absolute levels are considered accurate based on the validation performed, and, therefore, no separate rank ordering process is expected to be necessary. It is also noted that the new methods require more definition of both the landing gear and Krueger flap components.

The PAA effects were predicted in the same way as detailed in [10], using the best combination of data from both the LSAF series of experiments and the 14 by 22 N2A HWB experiment.

Compared to the engine rank ordering used in [10], an additional adjustment of engine source ranking was performed. These numerous changes had many offsetting impacts yielding the final cumulative noise of 40.2 EPNL dB reduction for the HWB-2016. However, while the cumulative result is nearly identical to the 40.3 EPNL dB reduction reported in [10] it is important to note that the predictions at the three certification points, as well as the component levels, show more substantial impacts.

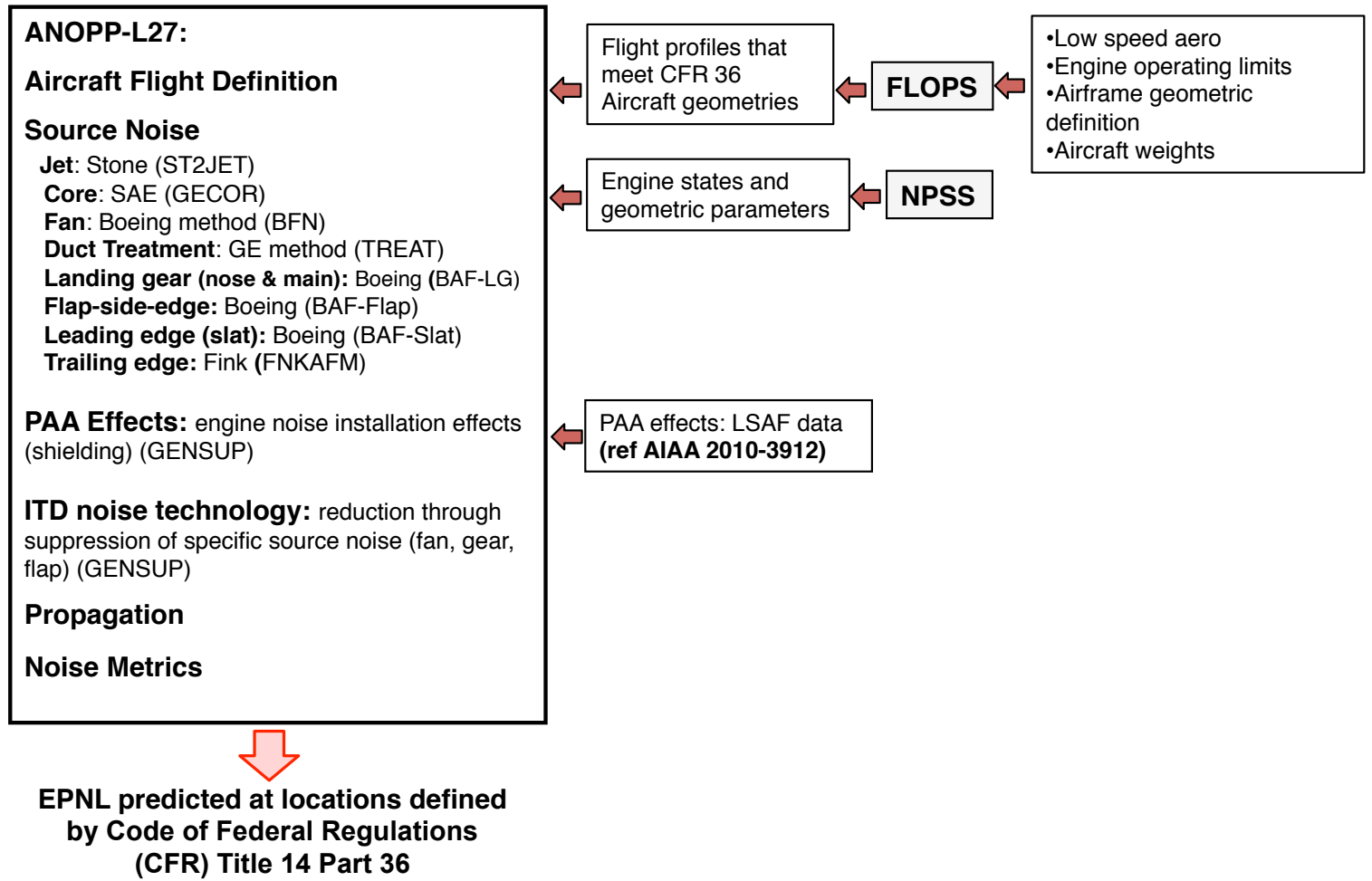

Figure 5. Overview of the noise assessment process used for HWB-2009. GENSUP is a module that allows the applications of noise deltas to account for noise technology and PAA effects. 


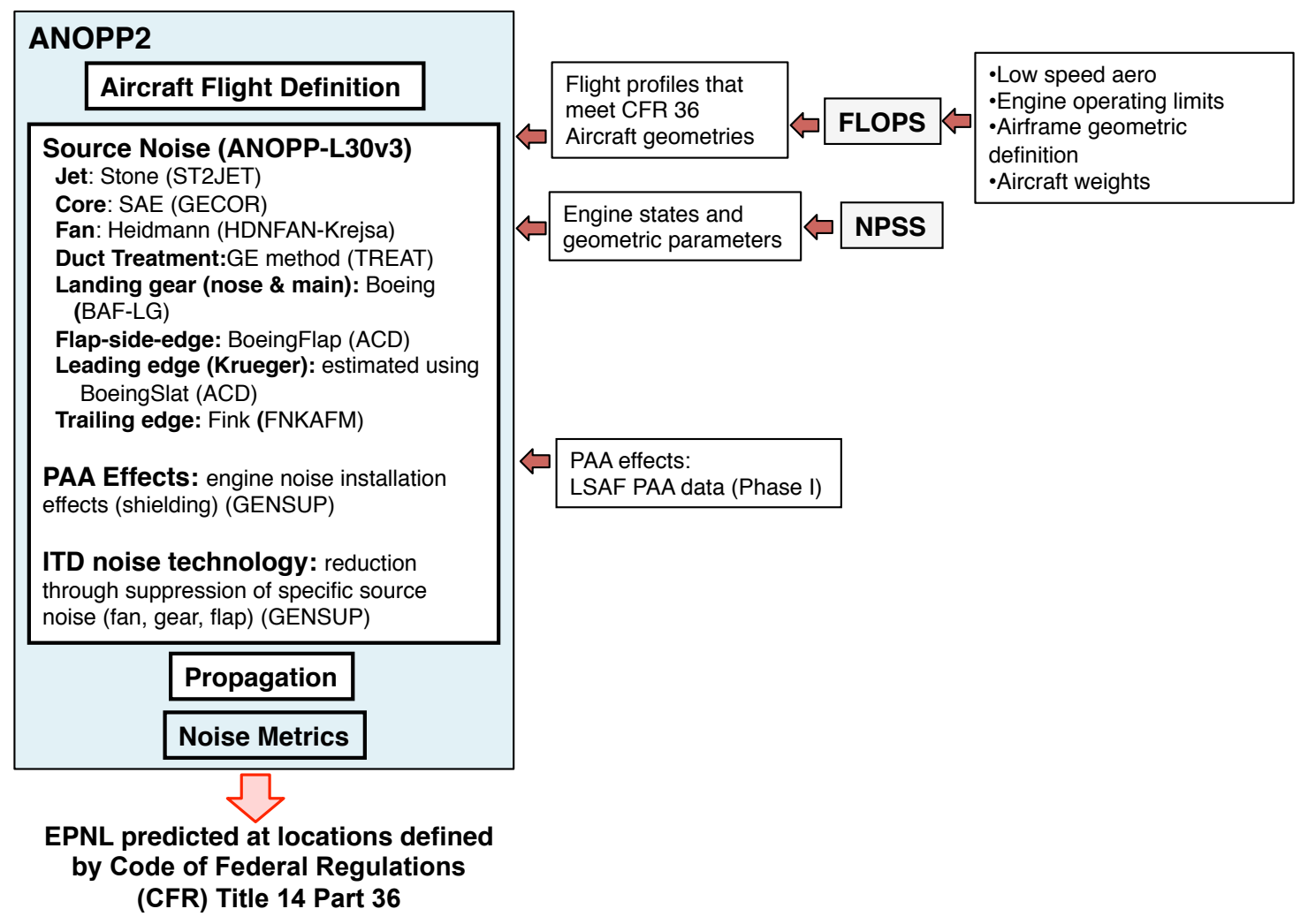

Figure 6. Overview of the noise assessment process used for HWB-2013. Acoustic Data Module (ACD) allows for external data to be inserted into the prediction process.

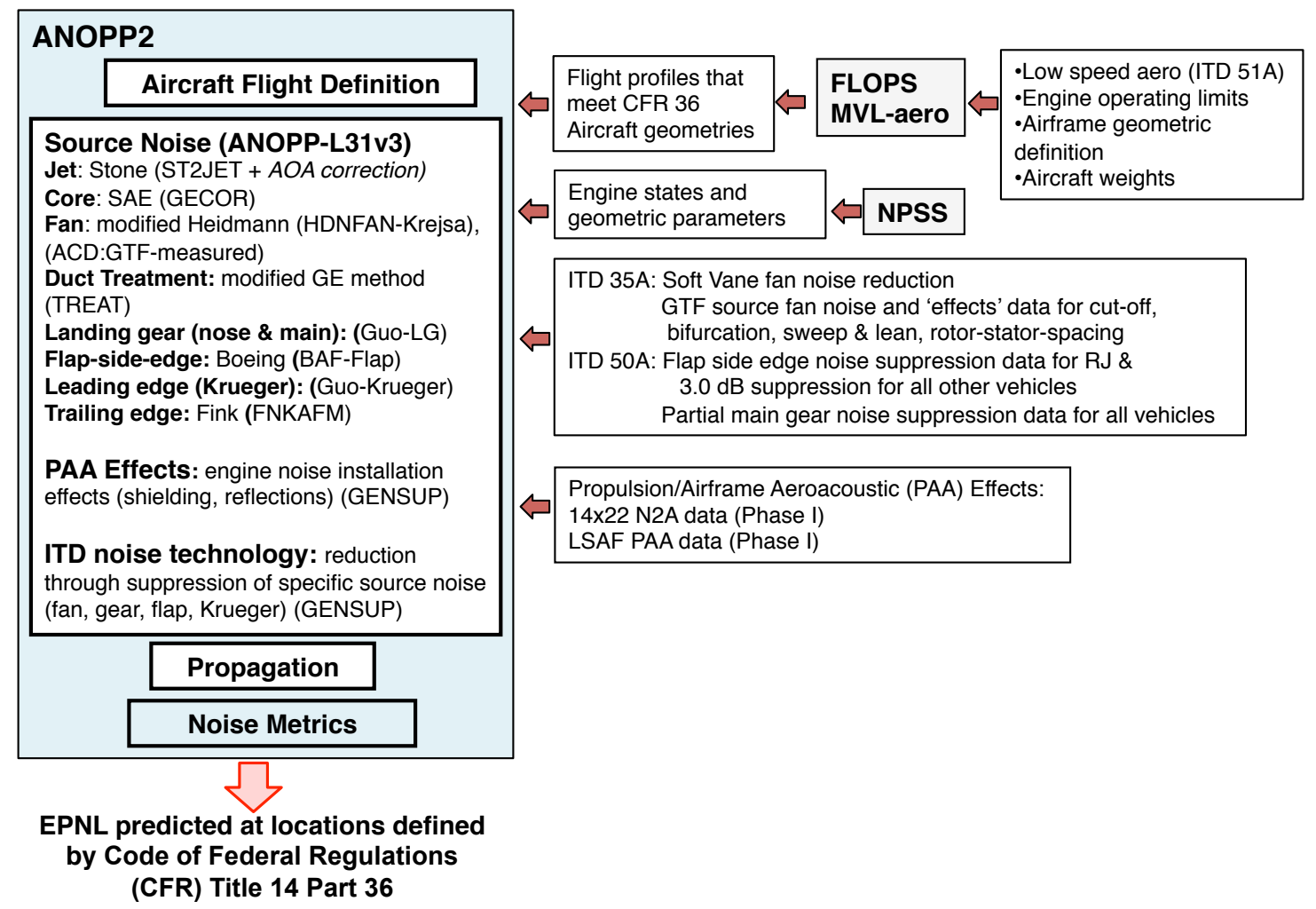

Figure 7. Overview of the noise assessment process used for the HWB-2016. 


\section{Summary of Noise Assessment Results}

Table 4 summarizes the Stage 3 certification limits for each aircraft of the three studies. Consistent with the decreasing takeoff gross weight (TOGW) listed in Table 1 for each vehicle, the Stage 3 certification limits are shown. The predicted values at each certification point are summarized in Table 5 together with the Stage 4 limit (Stage 3 minus $10 \mathrm{~dB}$ ) and the margin below Stage 4. To this point in the paper, the numerous changes in vehicle design for each study, technology level, prediction methods, experimental data, and other information have been listed, all of which influence the final results in Table 5. Of course, many of these factors can produce offsetting impacts at the aircraft system level.

The predictions of the approach certification point change the most, as seen in Table 5, likely the result of several significant factors. One factor is that the approach velocity increases from the very low 115 knots for the HWB-2009 to more realistic and higher speeds in the subsequent studies (Table 1). The airframe technology changes from a conventional slat leading edge to a Krueger flap. The airframe component prediction methods were also changed completely. And finally, the noise reduction for main the landing gear component was changed from about 5 EPNL dB to about 2 EPNL dB.

Sideline and cutback certification points are heavily influenced by engine technology, and the progression from the HWB-2009 with a GE90-like engine to the ultra high bypass ratio GTF-like engines of the HWB-2013 and HWB-2016 studies would be expected to produce very large changes. However, aircraft system noise is influenced by many other design parameters, technologies, and operational impacts. Most notably, based on improved aerodynamic design, the engine was moved closer to the trailing edge after the HWB-2009 study.

The values reported in Table 5 represent the best, single value or deterministic prediction based on the prediction method described up to this point in the paper.

Table 4. Summary of Stage 3 certification limits for each assessment study, EPNL dB.

\begin{tabular}{|l|c|c|c|}
\hline \multirow{2}{*}{} & \multicolumn{3}{|c|}{ Stage 3 Certification Limits } \\
\cline { 2 - 4 } & HWB-2009 & HWB-2013 & HWB-2016 \\
\hline Approach, AP & 104.84 & 104.65 & 104.51 \\
\hline Lateral or Sideline, SL & 101.51 & 101.31 & 101.15 \\
\hline $\begin{array}{l}\text { Flyover with Cutback, } \\
\text { CB }\end{array}$ & 98.90 & 98.58 & 98.33 \\
\hline
\end{tabular}

Table 5. Deterministic predicted noise level below the Stage 4 limit for each study, EPNL dB.

\begin{tabular}{|c|c|c|c|c|c|c|}
\hline Study & $\begin{array}{c}\text { Approach, } \\
\text { AP }\end{array}$ & $\begin{array}{c}\text { Lateral, } \\
\text { SL }\end{array}$ & $\begin{array}{c}\text { Flyover, } \\
\text { CB }\end{array}$ & Cumulative & $\begin{array}{c}\text { Cumulative } \\
\text { Stage 4 } \\
\text { Limit }\end{array}$ & $\begin{array}{c}\text { Margin } \\
\text { Below Stage } \\
\text { 4 }\end{array}$ \\
\hline HWB-2009 & 84.52 & 87.27 & 81.05 & 252.84 & 295.25 & 42.4 \\
\hline HWB-2013 & 80.12 & 84.15 & 81.09 & 245.36 & 294.54 & 49.2 \\
\hline HWB-2016 & 92.01 & 82.46 & 79.29 & 253.76 & 293.99 & 40.2 \\
\hline
\end{tabular}

\section{Aircraft System Noise Uncertainty Quantification}

\section{A. Framework}

In 2012, the NASA acoustics team reported a comprehensive assessment of the state of NASA prediction capabilities [30] representing a detailed documentation of a range of capabilities from empirical, semi-empirical, analytical, to high fidelity computational. However, [30] represents the status of NASA capabilities circa 2010 and does not capture the progress since that time, particularly during the ERA project. In addition, [30] includes uncertainty quantification of many experimental results and predictive methods for a range of aircraft noise components, but the uncertainty for the PAA effects and system noise was not comprehensively treated. For aircraft system noise prediction, a logical study was included of sensitivity to a limited range of key aircraft design and operation parameters. Therefore, an uncertainty quantification process for aircraft system noise prediction has been of particular need. This is all the more relevant because of the many advanced aircraft concept studies that have been performed in recent years, many of which report the possibility of very large noise reductions. Therefore, this paper will document the uncertainty quantification process for aircraft system noise prediction developed during ERA and compute 
the results for the three HWB studies in order to track the progress in reducing uncertainty for the HWB aircraft concept studied during ERA. From the 2009 to the 2016 noise assessments, the ERA team has been consistently focused on the $\mathrm{N}+2$ goal, representing an opportunity to compute uncertainty on a consistent basis. Specifically, the same uncertainty quantification process will be used for the three vehicles and noise assessment processes as they were computed in 2009, 2013, and 2016, respectively.

The framework of this aircraft system noise assessment uncertainty quantification process is established by several key objectives. First, this process will quantify the uncertainty of the system noise prediction but will not establish the uncertainty of the vehicle and engine design, state, or operational parameters. As such, this process does not quantify the sensitivity to any of the design, state, or operational parameters. The vehicle and engine design, state, and operational parameters are fixed as were provided by the system analysis teams to the system noise assessment team. Second, the total uncertainty will include the uncertainties from the modeling of individual elements and the overall system noise prediction process. Third, consistent with the objective of aircraft system noise, the uncertainty will be that of integrated technologies at the full scale, full fidelity aircraft level to the extent possible. However, in general, this does not include the impact of design refinement or of additional technology maturation. Therefore, the result does not represent an upper limit on the noise reduction potential of a particular aircraft concept and technology set.

\section{B. Overall Uncertainty Quantification Process}

Given the framework objectives above, the process begins by establishing an uncertainty for each prediction element within the aircraft system noise process. Based on the uncertainty, random probability distributions for each element are established. The system noise prediction computed in a direct Monte Carlo process for 10,000 simulations, and statistics are calculated for the predictions of the three certification points and the cumulative noise margin. The full prediction process is used for each simulation (no surrogate models are used). The uncertainties of the system level predictions are established at a 95\% confidence level. The implementation and interpretation of this process follow the discussion and related examples from [30 and 31].

Prediction elements necessary for the total HWB aircraft prediction include those for the noise sources, noise reduction technologies, and the PAA interactions. The noise sources include fan, jet, core, main and nose landing gear, Krueger flap leading edge, and trailing edge. (Note: HWB aircraft do not have trailing edge high lift flaps and hence prediction of flap-side-edge (shown in Figs. 5-7) is not performed.) Noise reduction technologies include the duct acoustic liner, soft vane acoustic liner applied to the stators, and a partial main landing gear fairing. The PAA interactions include primarily the acoustic scattering effects from shielding and reflection.

For each prediction element, the uncertainty for the prediction is established at a $95 \%$ confidence level. This uncertainty is established through one of four methods. Practically, the uncertainty established must reflect that there is a $95 \%$ probability that the next prediction at a spectral level (at any of the angles and frequencies required for the system noise) will be within \pm 2 standard deviations of a true value. In general, this is a difficult challenge for prediction methods. The four approaches are:

- Formulation method (with verification by reference data comparison)

- Reference data prediction test method

- Fixed by aircraft level information method or

- Inferred method.

The first method, formulation, involves establishing uncertainty of each modeling parameter or formulation within the prediction method followed by propagating these modeling uncertainties by direct Monte Carlo simulation to the element (component) level. The uncertainty quantities are then checked for consistency with the results of comparisons of the prediction results with relevant datasets. An example of the formulation method is found in [28]. The second method, reference data prediction test, involves the selection of a reference dataset and establishing the uncertainty of the prediction method based on the performance of the prediction method with the reference dataset. The third is a special situation where certification aircraft noise data, aircraft flight test data or other information is used to calibrate or fix the value of a prediction. In general, this is obviously not available for advanced concepts, but it is used in the HWB-2009 study for the engine sources only due to the framework of that study. The final method is the result of the fact that experimental data are used in several cases in a data-to-prediction process; that is the data are used as a prediction method. The uncertainty of this prediction at the aircraft level from a limited 
amount of experimental or computational data taken on a model system (that may have differences with the aircraft concept that it is applied to) has to be inferred based on knowledge of the experimental design, measurement uncertainty, and experience in developing semi-empirical predictions based on datasets.

For the second method, a hierarchy for the fidelity of reference datasets is established. From this hierarchy, the highest value reference datasets are chosen for each prediction element based on experience. The highest value reference datasets are those at full scale, full fidelity aircraft integrated level in flight commensurate with the aircraft system noise prediction objective. The hierarchy of reference datasets can be described as follows from highest to lowest fidelity:

- Full-scale, full-fidelity aircraft flight data,

- Model scale, higher fidelity integrated system experimental data,

- Model scale, high fidelity integrated sub-system experimental data,

- Isolated component experimental data.

Using one of the four element uncertainty approaches the standard deviation of uncertainty of each prediction element is determined. In general, the $95 \%$ confidence level is then established, represented by a normal distribution with a cut-off at $\pm 2 \sigma$ (standard deviations), except where noted. The cut-off prevents the very lowest probability occurrences.

All prediction element uncertainties are propagated to the aircraft system level by the direct Monte Carlo method with 10,000 simulations.

\section{Prediction Element Uncertainties}

For each of the three noise assessments and for each of the prediction elements, the element uncertainties are established in as consistent a manner as possible. Table 6 lists the prediction element uncertainties in terms of the standard deviation used for the HWB-2009 study including the implementation of the probability distribution. For example, this means that for a $95 \%$ confidence, the prediction of the PAA effect on jet noise (including pylon, chevron effect and shielding) is within $\pm 2 \sigma$ or $\pm 2 \mathrm{~dB}$ at any frequency and angle of the true (and unknown) value. It is important to note that while noise reduction from a shielded configuration may be the dominant effect there may be angles and frequencies where there can be noise increases due to the reflections from vertical control surfaces or from the high frequency effect that can occur with aggressively immersed chevrons.

In general, normal distributions are applied on all noise prediction elements. However, in the case where experimental data are used as a prediction method for noise reduction effects or technologies, a onesided normal distribution is implemented as a simplified type of skewed probability distribution. The distribution is normal, however, it is randomly sampled only allowing for less noise reduction. This feature is implemented to reflect the likely possibility that less noise reduction will occur upon full-scale, fullfidelity application when based on model-scale experiments where all the features of the full-scale design are not captured, experimental conditions are not exactly matching those for the full aircraft prediction, or the flight effects are not fully simulated. Typically, further development is required for the noise reduction technology to be fine-tuned for the specific application or to produce improved noise reduction levels.

Notable in Table 6 are the low standard deviations assigned to the engine sources: Fan Inlet, Fan Aft, Jet, and Core. This is the direct result of the process described earlier where the GE90 information was used to fix the levels and rank ordering of the engine noise sources. The standard deviation of $0.5 \mathrm{~dB}$ is, therefore, the result of a limit reflecting the experimental uncertainty of flight test data for a specific repeatable condition. There is no uncertainty assigned to the acoustic duct liner because that prediction is applied to the fan source noise before it is fixed by the GE90 information.

For all the PAA effects, the data of [4] were used in a data-to-prediction method for the HWB-2009 study as described in [3]. The experimental repeatability reported was very good at $\pm 0.25 \mathrm{~dB}$ for spectra at all angles and frequencies. However, for a system noise prediction, the data are used in a prediction even though there is not an exact match of all configuration features between model scale experiment and the full aircraft concept or even though all angles or conditions are not available from the experiment for the full aircraft flight path. As a result, the predictive uncertainty is not reflected by the experimental repeatability and, in general, will be larger. Ideally, according to the hierarchy, there would exist full-scale, full-fidelity flight test experimental data to measure the uncertainty of the data-to-prediction method or, in principle, any other prediction method applied for PAA effects. Of course, in general, that information will not exist for an advanced aircraft concept. In a companion publication, Burley et al. [32] reports a process 
to establish the uncertainty of PAA effects prediction and establishes the uncertainty values that are reported in Tables 6-8.

The most notable changes in element uncertainties for the HWB-2013 study are reflected in the engine source uncertainties shown in Table 7. These uncertainties are now much larger because this is now a true prediction for all the engine sources. The Kresja model is used for the fan source noise and is a robust semiempirical and well-documented fan noise prediction method [23]. However, in this case it is being used to predict fan noise of a design space (fan pressure ratio, rotor-stator spacing, blade design, etc.) that was not available in the development of the model.

Table 8 lists the element uncertainties for the final HWB-2016 study. Notable changes reflect that experimental data [33] is now used in a data-to-prediction process for the ultra high bypass ratio, geared fan noise in a process described in [10]. The PAA effects are predicted from a combination of the most relevant datasets from [25-27] and use the same uncertainty values from the process of [32]. New methods for the prediction of landing gear and Krueger flap noise were implemented and the uncertainty method was changed to a formulation process for both sources. The uncertainty determined for the prediction of main landing gear source noise was verified by the extensive validation reported in [28] including the full-scale, full-fidelity flight cases. The same formulation type uncertainty determination performed for landing gear in [28] was also applied to the nose gear and the Krueger flap sources to determine the values in Table 8. Separately, the uncertainty of the noise reduction partial main landing gear fairing is influenced by the continuation, at higher resolution, of the computational work reported in [34]. The uncertainty of the duct liner treatment, in this case with MDOF technology, is based on the inferred method and is influenced by a number of sources [30, 35-37] and is complicated by the absence of full-scale, full-fidelity engine data or flight data where the duct liner impact is clearly separable.

Table 6. HWB-2009 prediction element uncertainties.

\begin{tabular}{|c|c|c|c|c|c|}
\hline $\begin{array}{l}\text { Prediction } \\
\text { Element }\end{array}$ & Type & $\begin{array}{l}\text { Method } \\
\text { Used }\end{array}$ & $\begin{array}{c}\text { Standard } \\
\text { Deviation, } \\
\text { dB }\end{array}$ & Distribution & $\begin{array}{c}\text { Elements } \\
\text { Combined }\end{array}$ \\
\hline Fan Inlet & Source & Fixed & 0.5 & Normal & \\
\hline Fan Aft & Source & Fixed & 0.5 & Normal & \\
\hline Jet & Source & Fixed & 0.5 & Normal & \\
\hline Core & Source & Fixed & 0.5 & Normal & \\
\hline $\begin{array}{l}\text { Duct Liner } \\
\text { (SDOF and } \\
\text { DDOF) }\end{array}$ & $\begin{array}{l}\text { Noise } \\
\text { Reduction }\end{array}$ & N/A & $\begin{array}{l}\text { Included in } \\
\text { Fan Inlet } \\
\text { and Aft }\end{array}$ & & Fan Inlet, Fan Aft \\
\hline $\begin{array}{l}\text { Crown Pylon } \\
\text { Acoustic Liner }\end{array}$ & $\begin{array}{l}\text { Noise } \\
\text { Reduction }\end{array}$ & Inferred & 2 & One-sided normal & Fan Aft \\
\hline $\begin{array}{l}\text { Fan and Core } \\
\text { PAA Effect }\end{array}$ & PAA & Test & 2 & One-sided normal & $\begin{array}{l}\text { Fan Inlet, Fan Aft, } \\
\text { Core }\end{array}$ \\
\hline Jet PAA Effect & PAA & Test & 1 & One-sided normal & $\begin{array}{l}\text { Jet including } \\
\text { chevron and jet- } \\
\text { pylon effects }\end{array}$ \\
\hline Main Gear & Source & Test & 2 & Normal & \\
\hline $\begin{array}{l}\text { Aggressive } \\
\text { Landing Gear } \\
\text { Fairing }\end{array}$ & $\begin{array}{l}\text { Noise } \\
\text { Reduction }\end{array}$ & Inferred & 2 & One-sided normal & Main Gear \\
\hline Nose Gear & Source & Test & 2 & Normal & \\
\hline $\begin{array}{l}\text { Conventional } \\
\text { Slat }\end{array}$ & Source & Test & 3 & Normal & \\
\hline Trailing Edge & Source & Test & 3 & Normal & \\
\hline
\end{tabular}


Table 7. HWB-2013 prediction element uncertainties.

\begin{tabular}{|c|c|c|c|c|c|}
\hline $\begin{array}{c}\text { Prediction } \\
\text { Element }\end{array}$ & Type & $\begin{array}{l}\text { Method } \\
\text { Used }\end{array}$ & $\begin{array}{l}\text { Standard } \\
\text { Deviation, } \\
\text { dB }\end{array}$ & Distribution & $\begin{array}{l}\text { Elements } \\
\text { Combined }\end{array}$ \\
\hline Fan Inlet & Source & Test & 3 & Normal & \\
\hline Fan Aft & Source & Test & 3 & Normal & \\
\hline Jet & Source & Test & 3 & Normal & \\
\hline Core & Source & Test & 3 & Normal & \\
\hline $\begin{array}{l}\text { Duct Liner } \\
\text { (SDOF and } \\
\text { DDOF) }\end{array}$ & $\begin{array}{l}\text { Noise } \\
\text { Reduction }\end{array}$ & Inferred & 2 & Normal & Fan Inlet, Fan Aft \\
\hline $\begin{array}{l}\text { Soft Vane and } \\
\text { Over-the-Rotor } \\
\text { Acoustic Liner }\end{array}$ & $\begin{array}{l}\text { Noise } \\
\text { Reduction }\end{array}$ & Inferred & 0.5 & One-sided normal & Fan Inlet, Fan Aft \\
\hline $\begin{array}{l}\text { Fan and Core } \\
\text { PAA Effect }\end{array}$ & PAA & Test & 2 & One-sided normal & $\begin{array}{l}\text { Fan Inlet, Fan Aft, } \\
\text { Core }\end{array}$ \\
\hline Jet PAA Effect & PAA & Test & 1 & One-sided normal & Jet \\
\hline Main Gear & Source & Test & 2 & Normal & \\
\hline $\begin{array}{l}\text { Partial Landing } \\
\text { Gear Fairing }\end{array}$ & $\begin{array}{l}\text { Noise } \\
\text { Reduction }\end{array}$ & Inferred & 0.5 & One-sided normal & Main Gear \\
\hline Nose Gear & Source & Test & 2 & Normal & \\
\hline Krueger Flap & Source & Test & 3 & Normal & \\
\hline Trailing Edge & Source & Test & 3 & Normal & \\
\hline
\end{tabular}

Table 8. HWB-2016 prediction element uncertainties.

\begin{tabular}{|l|l|l|c|l|l|}
\hline \multicolumn{1}{|c|}{$\begin{array}{c}\text { Prediction } \\
\text { Element }\end{array}$} & \multicolumn{1}{|c|}{ Type } & \multicolumn{1}{|c|}{$\begin{array}{c}\text { Method } \\
\text { Used }\end{array}$} & $\begin{array}{c}\text { Standard } \\
\text { Deviation, } \\
\text { dB }\end{array}$ & \multicolumn{1}{|c|}{$\begin{array}{c}\text { Distributionents } \\
\text { Combined }\end{array}$} \\
\hline Fan Inlet & Source & Test & 2 & Normal & \\
\hline Fan Aft & Source & Test & 2 & Normal & \\
\hline Jet & Source & Test & 3 & Normal & \\
\hline Core & Source & Test & 3 & Normal & Fan Inlet, Fan Aft \\
\hline $\begin{array}{l}\text { Duct Liner } \\
\text { (MDOF) }\end{array}$ & $\begin{array}{l}\text { Noise } \\
\text { Reduction }\end{array}$ & Inferred & 2 & Normal & Fan Inlet, Fan Aft \\
\hline $\begin{array}{l}\text { Soft Vane } \\
\text { Acoustic Liner }\end{array}$ & $\begin{array}{l}\text { Noise } \\
\text { Reduction }\end{array}$ & Inferred & 0.5 & One-sided normal & Fan Inlet, Fan Aft, \\
\hline $\begin{array}{l}\text { Fan and Core } \\
\text { PAA Effect }\end{array}$ & PAA & Test & 2 & One-sided normal & Core \\
\hline Jet PAA Effect & PAA & Test & 1 & One-sided normal & Jet \\
\hline Main Gear & Source & Formulation & 1.4 & Normal & \\
\hline $\begin{array}{l}\text { Partial Landing } \\
\text { Gear Fairing }\end{array}$ & $\begin{array}{l}\text { Noise } \\
\text { Reduction }\end{array}$ & Inferred & 0.25 & One-sided normal & Main Gear \\
\hline Nose Gear & Source & Formulation & 1.6 & Normal & \\
\hline Krueger Flap & Source & Formulation & 2.7 & Normal & \\
\hline Trailing Edge & Source & Test & 3 & Normal & \\
\hline
\end{tabular}

\section{Aircraft System Noise Level Uncertainty Quantification}

The probabilistic aircraft system level noise levels are computed by the direct Monte Carlo method for 10,000 simulations for each of the three system noise assessments performed in 2009, 2013, and 2016 using the respective HWB vehicles (Table 1), noise assessment processes (Figures 5-7), and prediction element uncertainties (Tables 6-8).

For each of the Monte Carlo simulations, the predictions of the three certification conditions are performed independently by randomly sampling the prediction element distributions for each certification condition. The cumulative number is the sum of the three conditions (as shown for the deterministic 
predictions in Table 5). Therefore, for each of the three studies, there are 10,000 predictions each for the approach, flyover, and lateral points and, as a result, a total of 10,000 simulations predicting cumulative noise margin below the Stage 4 limit. Statistics can be computed at each of the three certification points for each aircraft noise component, total airframe noise level, total engine level with PAA effects, and total aircraft level. To make the presentation tractable and to reach the most important conclusion relative to the purpose of this paper, the presentation of statistics will be abbreviated.

Figure 8 shows the cumulative noise for the HWB-2009 study as a function of the 10,000 simulations. Notably, the mean of the probabilistic prediction is not the same as that of the deterministic prediction from Table 5. This difference is due primarily to the several one-sided uncertainties at the element level. As will be quantified later, it is also in large part attributable to the approach point and the prediction of the main gear source noise. Due to a lack of knowledge at the time of the HWB-2009 study, the local velocity was not properly predicted amounting to approximately a $5 \mathrm{~dB}$ lower noise predicted at the component level [5, 6]. This correction has been included in this uncertainty quantification as a bias offset in the main landing gear prediction. As such, it impacts the probabilistic mean with the effect of reducing the amount of noise reduction and reducing the margin to the Stage 4 limit. Figure 8 also provides the accumulated standard deviation for the cumulative noise and two measures of the distribution of the cumulative noise histogram, skewness and kurtosis. A skewness ratio of 0 and a kurtosis of 3 would correspond to a perfectly Gaussian distribution for the cumulative noise predictions. As can be seen by the plots, both the skewness and the kurtosis are offset somewhat and are likely a result, again, of the number of one-sided element distributions that have been used. As is expected, the statistics require about 3000-5000 simulations before approaching the final value. The standard deviation of the distribution of the cumulative noise simulations initially is above $1.4 \mathrm{~dB}$ before finally approaching the final value of 1.27 .
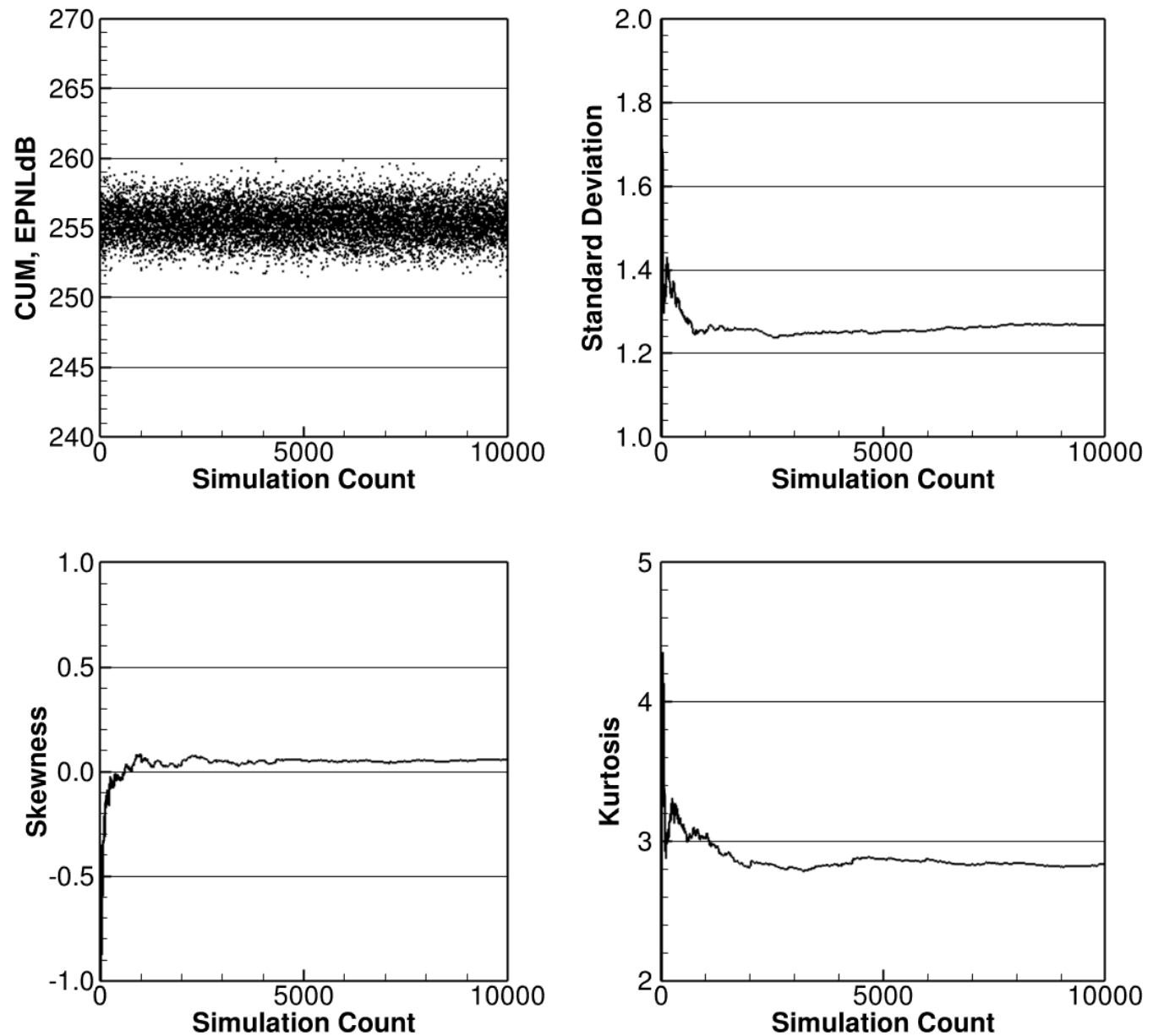

Figure 8. Cumulative noise for the HWB-2009 and distribution statistics as a function of simulation count. 
Figure 9 plots the same values now for the HWB-2013 system noise prediction. Similar observations can be made for the skewness and kurtosis values. However, the offset between the probabilistic mean and the deterministic cumulative values is much smaller. In this case, the rank ordering of the sources partially offsets the impact of the one-sided uncertainties for the PAA effects and noise reduction technologies. Notably, the scatter of the cumulative values and the associated standard deviation are much higher as compared to the HWB-2009, as expected because the HWB-2013 was the first true $\mathrm{N}+2$ prediction without the benefit of engine noise calibration or ranking information. The final value for the standard deviation is now $3.06 \mathrm{~dB}$.

The same presentation for the HWB-2016 predictions is made in Figure 10. The standard deviation approaches the final value of $2.42 \mathrm{~dB}$ with distributions that are close to normal as measured by the skewness and kurtosis values reflecting, again, some impact of the several one sided element uncertainties that continue to be prominent contributors to the system noise prediction results.
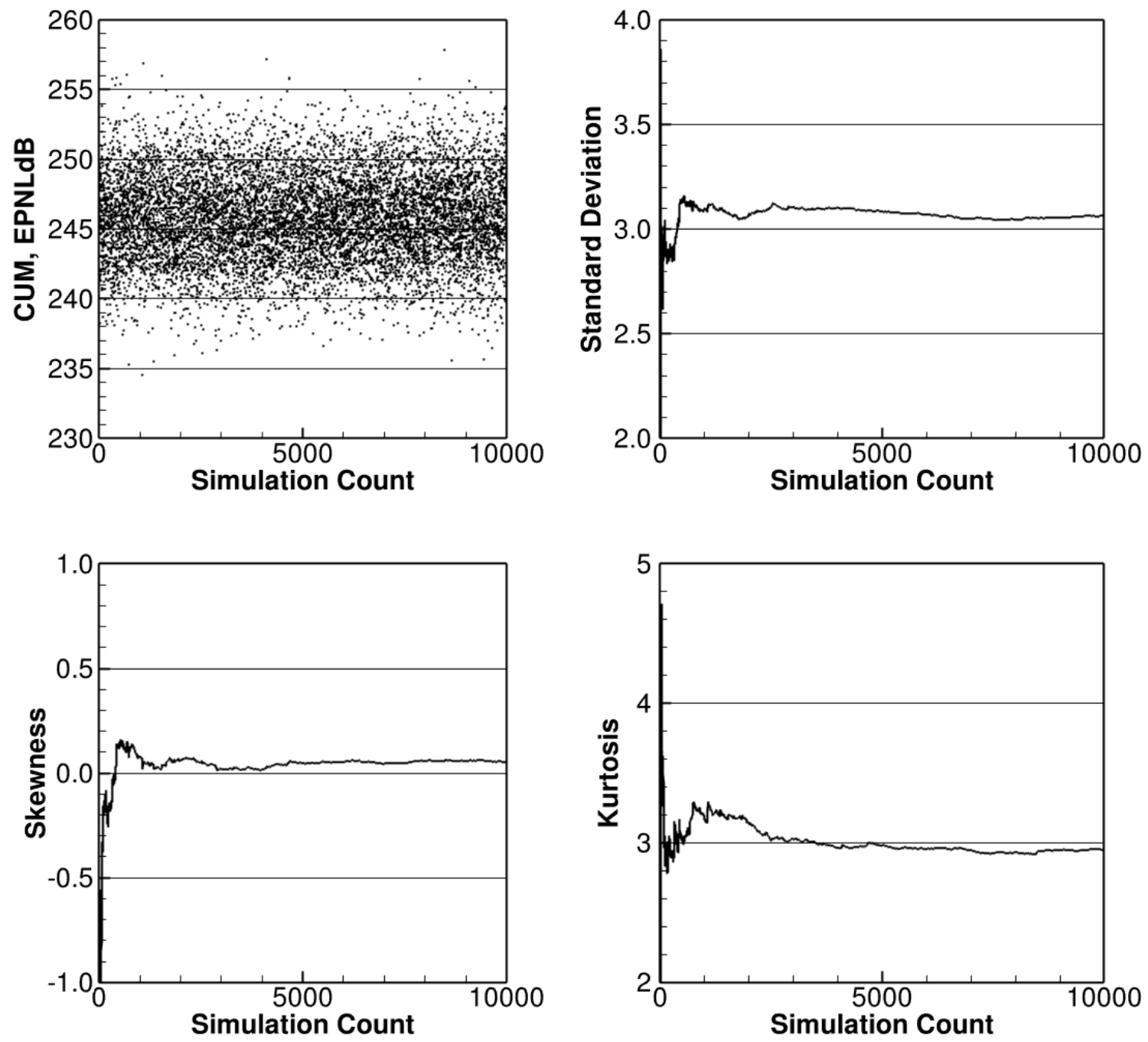

Figure 9. Cumulative noise for the HWB-2013 and distribution statistics as a function of simulation count. 

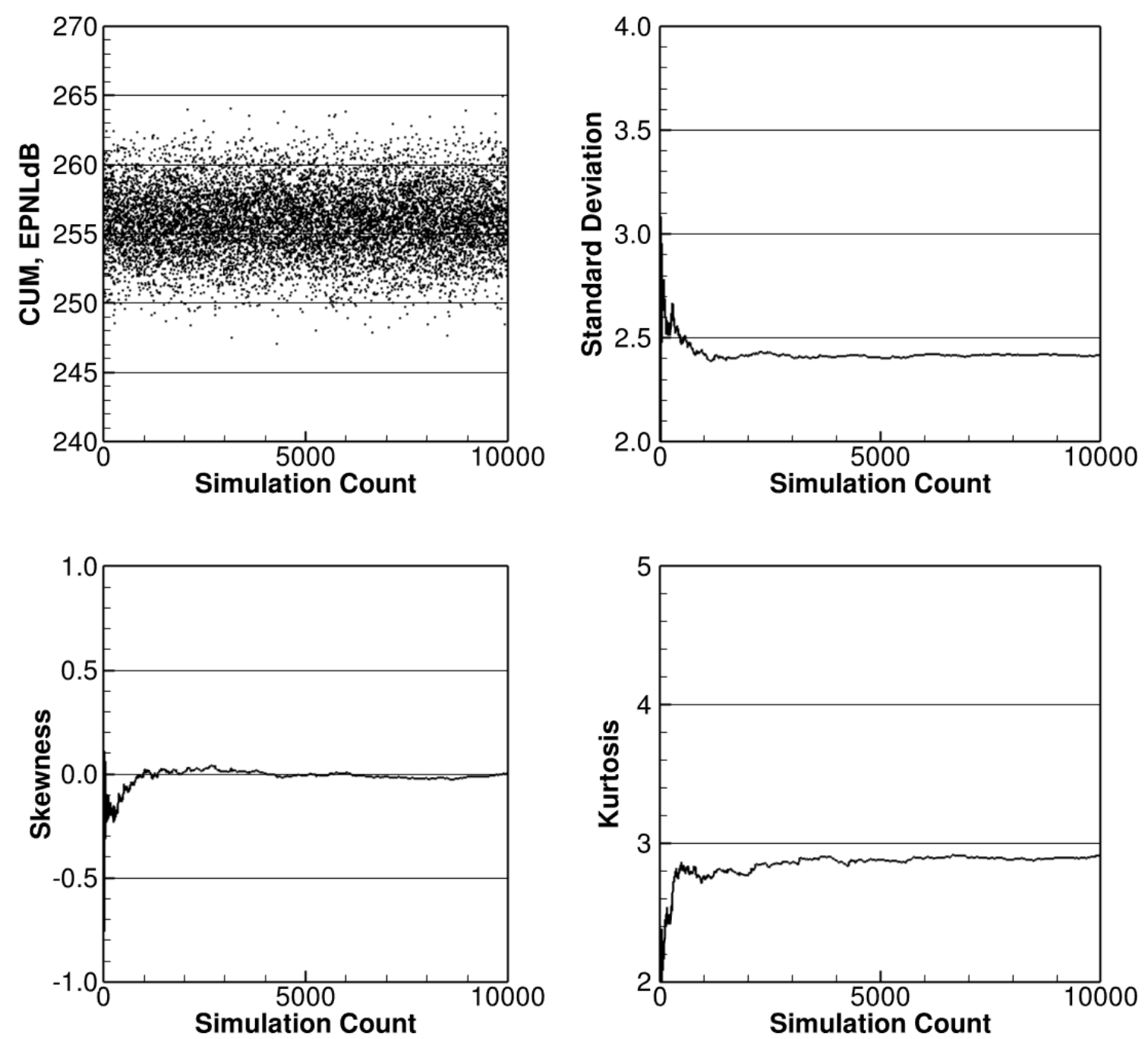

Figure 10. Cumulative noise for the HWB-2016 and distribution statistics as a function of simulation count.

Table 9 presents a summary of these statistics for the probabilistic mean cumulative values in addition to the probabilistic mean values calculated for each of the three certification points. The standard deviation of the HWB-2009 is quite low due to the framework of the study. The HWB-2013 standard deviation is much higher reflecting that it is the first true $\mathrm{N}+2$ prediction without benefit of any aircraft level calibration. And finally, the standard deviation for the HWB-2016 study shows reduction due to the many improvements during the final three years of ERA.

Table 9. Quantified uncertainties for probabilistic system noise prediction results, EPNL dB.

\begin{tabular}{|c|c|c|c|c|c|c|c|c|c|}
\hline Study & AP & $\begin{array}{c}\text { Std } \\
\text { Dev }\end{array}$ & SL & $\begin{array}{c}\text { Std } \\
\text { Dev }\end{array}$ & CB & $\begin{array}{c}\text { Std } \\
\text { Dev }\end{array}$ & Cumulative & $\begin{array}{c}\text { Std Dev } \\
\text { CUM }\end{array}$ & $\begin{array}{c}\text { CUM Margin } \\
\text { Below Stage 4 }\end{array}$ \\
\hline HWB-2009 & 85.10 & 0.98 & 88.31 & 0.57 & 82.04 & 0.59 & 255.45 & 1.27 & 39.8 \\
\hline HWB-2013 & 80.49 & 1.29 & 83.50 & 1.98 & 81.82 & 1.97 & 245.81 & 3.06 & 48.7 \\
\hline HWB-2016 & 92.18 & 1.16 & 83.50 & 1.39 & 80.26 & 1.61 & 255.94 & 2.42 & 38.1 \\
\hline
\end{tabular}


An additional step is made to establish the total uncertainty band, at the $95 \%$ confidence level, based on the statistics of the Monte Carlo simulation. This step follows examples from [30 and 31] with the 95\% confidence level at twice the standard deviation of the cumulative noise distribution. The offset between the deterministic and probabilistic cumulative noise predictions reflects the probable weighting toward a louder aircraft from implementation at the full-scale, full-fidelity aircraft of the technology "in hand" without further refinement. This offset shifts the uncertainty band toward a lower margin (louder) relative to the Stage 4 limit. Table 10 summarizes the implementation of this reasoning. The deterministic prediction is still considered the single, best system noise prediction because it uses the actual data available for the noise reduction technologies included. Therefore, based on the probabilistic results, the uncertainty band is assigned to the single best, deterministic, prediction as shown in Table 10 including the offset.

Specifically interpreting the results in Table 10 would mean, using the HWB-2016 as the example, the single, best prediction of the cumulative system noise would be 40.2 EPNL dB with a $95 \%$ probability that the next prediction would fall within the range of $+2.7 \mathrm{~dB}$ to $-6.9 \mathrm{~dB}$ around $40.2 \mathrm{EPNL} \mathrm{dB}$. The highest probabilities would cluster closer to the probabilistic mean of 38.1 EPNL dB including the deterministic value of 40.2 EPNL dB.

If further refinement of the noise reduction technology is accomplished to apply the technology to the full-scale, full-fidelity aircraft that is being predicted, then the one-sided normal distributions (Tables 6-8) would be changed to normal distributions, the offset between the deterministic and probabilistic mean values would diminish, and the $95 \%$ confidence band would become symmetrical.

Table 10. Determination of uncertainty of cumulative system noise, EPNL dB.

\begin{tabular}{|c|c|c|c|c|c|r|}
\hline Study & $\begin{array}{c}\text { Deterministic } \\
\text { Cumulative } \\
\text { Prediction }\end{array}$ & $\begin{array}{c}\text { Probabilistic } \\
\text { Cumulative } \\
\text { Prediction }\end{array}$ & Offset & $\begin{array}{c}\text { Std Dev } \\
\text { of } \\
\text { CUM }\end{array}$ & $\begin{array}{c}\text { 95\% } \\
\text { Confidence } \\
\text { Band }\end{array}$ & $\begin{array}{c}\text { Deterministic } \\
\text { Prediction with } \\
\text { 95\% Confidence } \\
\text { Band (including } \\
\text { Offset) }\end{array}$ \\
\hline $\begin{array}{c}\text { HWB- } \\
\mathbf{2 0 0 9}\end{array}$ & 42.4 & 39.8 & -2.6 & 1.27 & \pm 2.5 & $42.4+0.0$ \\
\hline $\begin{array}{c}\text { HWB- } \\
\mathbf{2 0 1 3}\end{array}$ & 49.2 & 48.7 & -0.5 & 3.06 & \pm 6.1 & $49.2+5.6$ \\
\hline $\begin{array}{c}\text { HWB- } \\
\mathbf{2 0 1 6}\end{array}$ & 40.2 & 38.1 & -2.1 & 2.42 & \pm 4.8 & $40.2+2.7$ \\
\hline
\end{tabular}

\section{E. Context for the Uncertainty Quantification}

As a measure of progress in reducing the uncertainty of the deterministic predictions of HWB system noise during ERA, the reduction of the 95\% confidence band from the HWB-2013 to that of the HWB2016 is most logical because the vehicle design and technology level were on the most similar basis. As a result, a reduction from a total uncertainty band of 12.2 to 9.6 EPNL dB was achieved. For context, the lower limit that could be achievable for the prediction uncertainty band is proposed as similar to the normal distribution of flight test measurements that would be acquired if the predicted HWB aircraft were built and flight tested. The cumulative noise is the sum of three independent measurements. Assuming a normal distribution of flight test noise measurements that are repeated at the same conditions to the extent possible, a standard deviation of $0.5 \mathrm{~dB}$ is deemed reasonable based on a variety of flight test measurement experiences as examples [38-41]. This corresponds to a $95 \%$ probability that the next measurement of a repeat flight test at one of the three certification conditions will fall within a band of $\pm 1.0 \mathrm{~dB}$. If each of the three certification conditions has a standard deviation of $0.5 \mathrm{~dB}$ then, for the sum of three independent normally distributed experiments the cumulative noise measurement will have a standard deviation of 0.9 $\mathrm{dB}$ (rounded up). This would then correspond to a $95 \%$ confidence band of $\pm 1.8 \mathrm{~dB}$ for cumulative noise of an aircraft or a total band of 3.6 EPNL dB. This is proposed as the lower limit or target for the reduction of uncertainty on the prediction of the system noise of an advanced aircraft at the conceptual design level.

An important note should be made in regard to progress over the full length of ERA. The HWB-2009 study is not included in Table 11 due to the special purpose of that study, as has been described, and the resulting lower level of uncertainty. If the experiments of [4] had not been available at the very beginning of ERA and the vehicle and engine definition had been sufficient for an assessment in 2009, then, 
undoubtedly the $95 \%$ confidence band on that study would have been considerably larger than the 12.2 EPNL dB of the HWB-2013 study due to the very high uncertainty of PAA predicted effects and PAA noise reduction technology. Therefore, the full progress over the full length of ERA should reflect this much larger progress even though it cannot be numerically demonstrated without another study to reflect the PAA effect prediction uncertainty prior to 2009 and the experiments of [4].

Table 11. Progress in reducing uncertainty during ERA and a proposed target for the lower limit of uncertainty for the prediction of cumulative noise of conceptual aircraft designs, EPNL dB.

\begin{tabular}{|c|c|c|c|}
\hline & Std Dev of CUM Noise & $\mathbf{9 5 \%}$ Confidence Level & $\begin{array}{c}\text { Total 95\% Confidence } \\
\text { Band (with Offset) }\end{array}$ \\
\hline HWB-2013 & 3.06 & \pm 6.1 & 12.2 \\
\hline HWB-2016 & 2.42 & \pm 4.8 & 9.6 \\
\hline $\begin{array}{c}\text { Target and assumed } \\
\text { lower limit for } \\
\text { cumulative noise } \\
\text { uncertainty of } \\
\text { conceptual aircraft } \\
\text { design }\end{array}$ & 0.9 & \pm 1.8 & 3.6 \\
\hline
\end{tabular}

The discussion immediately above has to do with the uncertainty of the system noise prediction of cumulative noise for an advanced aircraft at the conceptual level of design, in this case an aircraft with a 2025 target for entry-into-service. Additional context to the calculated uncertainty for an advanced aircraft can be made with the example of the prediction of an existing aircraft, a 777-200 with GE85B engines. Prior to ERA, many of the source noise methods in ANOPP have been developed largely based on databases that are of technologies similar to those on this aircraft. Recent modeling improvements for landing gear prediction and for the explicit prediction of the PAA effects (reflection of aft engine noise sources from the wing) increase the fidelity of a prediction for this aircraft configuration. Certification data exist for this aircraft and represent a measure of the accuracy of the prediction at the full-scale, full-fidelity aircraft level for each certification point and for the cumulative noise, as shown in Table 12. In this example, it is important to note that the prediction is performed without any use of the certification data or any additional data (engine source ranking such as used in the HWB-2009 prediction) to calibrate the ANOPP prediction. As can be seen from Table 12, the results are very good with the largest difference of 1.4 EPNL dB at the lateral point and a difference in cumulative noise of $3.3 \mathrm{EPNL} d \mathrm{~B}$, a value that is consistent with the target listed in Table 11.

Table 12. System noise prediction results for an existing conventional aircraft where published certification data exist, EPNL dB.

\begin{tabular}{|l|c|c|c|c|}
\hline & Approach, AP & Lateral, SL & Flyover, CB & $\begin{array}{c}\text { Cumulative } \\
\text { Noise }\end{array}$ \\
\hline $\begin{array}{l}\text { 777-200-GE85B } \\
\text { best ANOPP } \\
\text { prediction without } \\
\text { calibration }\end{array}$ & 97.0 & 93.6 & 91.2 & 281.8 \\
\hline $\begin{array}{l}\text { 777-200-GE85B } \\
\text { reported } \\
\text { certification }\end{array}$ & 98.1 & 95.0 & 92.0 & 285.1 \\
\hline Difference & 1.1 & 1.4 & 0.8 & 3.3 \\
\hline
\end{tabular}




\section{Conclusions}

System noise prediction for advanced aircraft concepts presents unique challenges. For the ERA project, a deterministic aircraft system noise prediction process was developed to enable the high fidelity system noise assessment of advanced aircraft concepts including, most notably, the challenge of unconventional configurations. The process developed is very detailed including design features and details not typically included at the conceptual level. The process builds upon the best system noise methods available to NASA for each element of the prediction together with extensive databases for PAA effects, ultra high bypass ratio fan source noise, and several noise reduction technologies. New prediction element methods, specifically for the airframe components of landing gear and Krueger flap were added.

In addition, a probabilistic uncertainty quantification process for aircraft system noise prediction has been developed using a direct Monte Carlo simulation. The uncertainty applies only to the noise prediction and not to the models of the aircraft design or flight path. The uncertainty quantification process includes a recommended approach to establishing the uncertainties of each prediction element. The uncertainty of each prediction element is determined, wherever possible, by testing prediction methods against reference datasets that have been selected based on a hierarchy of fidelity and integrated system complexity.

The uncertainty quantification process is applied to the system noise predictions of NASA advanced HWB aircraft subsonic transport concepts performed at three specific points in time from 2009 to 2016. As a measure of progress in reducing the uncertainty of HWB aircraft system noise, on the most consistent basis, a reduction from a total uncertainty band of 12.2 to 9.6 EPNL dB was achieved from 2013 to 2016. The true measure of progress in reducing prediction uncertainty over the full length the ERA project, from 2009 to 2016, however, cannot be calculated without an additional study using the very limited information that was available prior to 2009. If this additional study were to be done, given the lack of PAA effect prediction methods or data that existed prior to 2009 , the result would show a much larger uncertainty as compared to the uncertainty band of 12.2 EPNL dB reported in the HWB-2013 study. Without a quantitative study, it is estimated that this pre-2009 uncertainty band would be approximately 16 EPNL dB based on insight into the pre-2009 PAA information and study results. With this estimate as the starting point, then the progress over the course of ERA reduced the system noise prediction uncertainty band by half. And finally, the lower limit for the uncertainty band on cumulative noise prediction is proposed as 3.6 EPNL $\mathrm{dB}$ and is a target.

The system noise uncertainty quantification process developed here provides a consistent method for providing a best available, rigorous noise assessment of advanced aircraft concepts together with a quantified uncertainty on the prediction. As the aircraft concept, experimental data, and the noise assessment process itself develop in the future, progress in reducing the uncertainty can be tracked toward the goal. In addition, the insight developed by the technology and system noise prediction experts that have the most in-depth knowledge together with the whole prediction and uncertainty results can also provide the most effective technical strategy to increase noise reduction together with reduced uncertainty.

\section{Acknowledgments}

This aircraft system noise assessment for the ERA N+2 portfolio of advanced technology concepts has been a significant undertaking over a multi-year period. The authors gratefully acknowledge that this high fidelity assessment of conceptual level aircraft has benefited greatly from the contributions of many. Therefore, the authors would like to thank the ERA ITD leads and industry partners, and the entire ERA System Analysis team. The authors wish to give a particular thanks to ERA project manager, Dr. Fay Collier, for his vision and leadership throughout the six years of ERA and for specifically stimulating this topic of uncertainty quantification. A special thank you to John Rawls and Stuart Pope of the Aeroacoustics Branch for contributions throughout the calculations for this study and for the implementation of many improvements to the ERA noise assessment and uncertainty quantification process. The authors also give a special acknowledgment to Michael Jones for helpful discussions on experimental uncertainty quantification.

\section{References}


1. Collier, F.S., Thomas, R.H., Nickol, C.L, Lee, Chi-Ming, and Tong, M., "Environmentally Responsible Aviation Real Solutions for Environmental Challenges Facing Aviation," $27^{\text {th }}$ International Congress of the Aeronautical Sciences, Paper No. 802, Nice, France, 19-24 September, 2010.

2. Hill, G.A., and Thomas, R.H., "Challenges and Opportunities for Noise Reduction Through Advanced Aircraft Propulsion Airframe Integration and Configurations," presented at the $8^{\text {th }}$ CEAS Workshop on Aeroacoustics of New Aircraft and Engine Configurations, Budapest, Hungary, Nov. 11-12, 2004.

3. Thomas, R. H., Burley, C. L., and Olson, E. D., "Hybrid Wing Body Aircraft System Noise Assessment with Propulsion Airframe Aeroacoustic Experiments," International Journal of Aeroacoustics, Vol. 11 (3+4), pp. 369410, 2012.

4. Czech, M. J., Thomas, R. H., and Elkoby, R., "Propulsion Airframe Aeroacoustic Integration Effects of a Hybrid Wing Body Aircraft Configuration," International Journal of Aeroacoustics, Vol. 11 (3+4), pp. 335-368, 2012.

5. Bonet, J. T., Schellenger, H. G., Rawdon, B. K., Elmer, K. R., Wakayama, S. R., Brown, D. \& Guo, Y. P., "Environmentally Responsible Aviation (ERA) Project - N+2 Advanced Vehicle Concepts Study and Conceptual Design of Subscale Test Vehicle (STV)," NASA Contract Report 2013-216519, 2013.

6. Guo, Y.P., Burley, C.L., and Thomas, R.H., "On Noise Assessment for Blended Wing Body Aircraft," AIAA Paper No. 2014-365.

7. Burley, C.L., Brooks, T.F., Hutcheson, F.V., Doty, M.J., Lopes, L.V., Nickol, C.L., Vicroy, D.D., and Pope, D.S., "Noise Scaling and Community Noise Metrics for the Hybrid Wing Body Aircraft," AIAA Paper 2014-2626.

8. Thomas, R.H. and Burley, C.L., "Progress Toward the N+2 Noise Goal: HWB Propulsion Airframe Aeroacoustics Boeing/NASA Low Speed Aeroacoustics Facility Experiment and System Noise Assessment," presentation to the NASA Fundamental Aeronautics Program Third Annual Meeting, Atlanta, Georgia, September 29-October 1, 2009.

9. Nickol, C.L., and Haller, W.J., "Assessment of the Fuel Burn Reduction Potential of Advanced Subsonic Transport Concepts for NASA's Environmentally Responsible Aviation Project," AIAA Paper 2016-1030, SciTech 2016 Conference, January, 2016.

10. Thomas, R.H., Burley, C.L., and Nickol, C.L., "Assessment of the Noise Reduction Potential of Advanced Subsonic Transport Concepts for NASA’s Environmentally Responsible Aviation Project,” AIAA Paper 2016-0863, SciTech 2016 conference, January, 2016.

11. Nickol, C.L. and McCullers, L.A., "Hybrid Wing Body Configuration System Studies," AIAA Paper 2009-0931.

12. Gern, F.H., "Improved Aerodynamic Analysis for Hybrid Wing Body Conceptual Design Optimization," AIAA Paper 2012-0249.

13. Gern, F.H., "Finite Element Based HWB Centerbody Structural Optimization and Weight Prediction," AIAA Paper 2012-1606.

14. Nickol, C.L., "Hybrid Wing Body Configuration Scaling Study," AIAA Paper 2012-0337.

15. McCullers, L, "Aircraft Configuration Optimization Including Optimized Flight Profiles," Proceedings of the Symposium of Recent Experiences in Multidisciplinary Analysis and Optimization, NASA CP 2327, April 1984.

16. Ozoroski, T.A., "Description, Usage, and Validation of the MVL-15 Modified Vortex Lattice Analysis Capability," NASA/CR-2015-218969, November 2015.

17. Lytle, J.K., "Numerical Propulsion System Simulation: An Overview," NASA TM 209915, 2000.

18. Tong, M.T., and Naylor, B.A., "An Object-Oriented Computer Code for Aircraft Engine Weight Estimation," GT2008-50062, ASME Turbo-Expo June, 2008.

19. Flamm, J., James, K., and Bonet, J., "Overview of ERA Integrated Technology Demonstration (ITD) 51A UltraHigh Bypass (UHB) Integration for Hybrid Wing Body (HWB)," AIAA Paper 2016-0007.

20. Vicroy, D.D., Dickey, E., Princen, N., and Beyar, M., "Overview of Low-Speed Aerodynamic Tests on a 5.75\% Scale Blended-Wing-Body Twin Jet Configuration,” AIAA Paper 2016-0009.

21. Guo, Y.P., Brusniak, L., Czech, M.J., and Thomas, R.H., "Hybrid Wing-Body Aircraft Slat Noise," AIAA Journal, 1-11, 10.2514/1.J052540, posted online 11 October 2013.

22. Lopes, L.V., and Burley, C.L., "Design of the Next Generation Aircraft Noise Prediction Program: ANOPP2," AIAA Paper 2011-2854.

23. Krejsa, E.A. and Stone, J.R., "Enhanced Fan Noise Modeling for Turbofan Engines," NASA/CR-2014-218421, December, 2014.

24. Guo, Y.P., Nickol, C.L., and Thomas, R.H., "Noise and Fuel Burn Reduction Potential of an Innovative Subsonic Transport Configuration," AIAA Paper 2014-257.

25. Thomas, R.H., Czech, M.J., and Doty, M.J., "High Bypass Ratio Jet Noise Reduction and Installation Effects Including Shielding Effectiveness," AIAA 2013-541.

26. Doty, M.J., Brooks, T.F., Burley, C.L., Bahr, C.J., and Pope, D.S., "Jet Noise Shielding Provided by a Hybrid Wing Body Aircraft," AIAA 2014-2625.

27. Hutcheson, F.V., Brooks, T.F., Burley, C.L., Bahr, C.J., Stead, D.J., and Pope, D.S., "Shielding of Turbomachinery Broadband Noise by a Hybrid Wing Body Aircraft Configuration," AIAA Paper 2014-2624.

28. Guo, Y.P., Burley, C.L., and Thomas, R.H., "Landing Gear Noise Prediction and Analysis for Tube-and-Wing and Hybrid Wing Body Aircraft,” AIAA Paper 2016-1273, SciTech 2016, January, 2016.

29. Guo, Y.P., Burley, C.L., and Thomas, R.H., "Modeling and Prediction of Krueger Device Noise," AIAA paper to appear at the $22^{\text {nd }}$ AIAA/CEAS Aeroacoustics Conference, Lyon, France, May, 2016. 
30. Dahl, M.D. editor, Assessment of NASA's Aircraft Noise Prediction Capability, NASA TP-2012-215653, July 2012.

31. Coleman, H.W. and Steele, W. G., Experimentation and Uncertainty Analysis for Engineers, $2^{\text {nd }}$ edition, John Wiley \& Sons, New York, 1999.

32. Burley, C.L., Thomas, R.H., and Guo, Y.P., "Acoustic Scattering Prediction for Aircraft System Noise Assessment," AIAA paper to appear at the $22^{\text {nd }}$ AIAA/CEAS Aeroacoustics Conference, Lyon, France, May, 2016.

33. Van Zante, D.E., and Suder, K.L., "Environmentally Responsible Aviation: Propulsion Research to Enable Fuel Burn, Noise and Emissions Reduction," ISABE-2015-20209, October, 2015.

34. Fares, E., Casalino, D., and Khorrami, M.R., "Evaluation of Airframe Noise Reduction Concepts via Simulations using a Lattice-Boltzmann Approach,” AIAA Paper 2015-2988, June, 2015.

35. Kontos, K.B., Kraft, R.E., and Gliebe, P.R., "Improved NASA-ANOPP Noise Prediction Computer Code for Advanced Subsonic Propulsion Systems, Volume 2: Fan Suppression Model Development," NASA CR-202309, December, 1996.

36. Sutliff, D.L., Nark, D.M., and Jones, M.G., "Efficacy of a Multiple Degree of Freedom Acoustic Liner Installed in the Bypass of a Scale Model High Speed Fan," AIAA paper to appear at the $22^{\text {nd }}$ AIAA/CEAS Aeroacoustics Conference, Lyon, France, May, 2016.

37. Nark, D.M., Jones, M.G., and Sutliff, D.L., "Further Development and Assessment of a Broadband Liner Optimization Process," AIAA paper to appear at the $22^{\text {nd }}$ AIAA/CEAS Aeroacoustics Conference, Lyon, France, May, 2016.

38. Nesbitt, E., Mengle, V., Czech, M., Callender, B., and Thomas, R., "Flight Test Results for Uniquely Tailored Propulsion-Airframe Aeroacoustic Chevrons: Community Noise," AIAA Paper 2006-2438.

39. Elkoby, R., Brusniak, L., Stoker, R.W., Khorrami, M.R., Abeysinghe, A., and Moe, J.W., “Airframe Noise Results from the QTD II Flight Test Program," AIAA paper 2007-3457.

40. Guerin, S. and Michel, U., "Aero-engine Noise Investigation from Flight Tests,” AIAA paper 2006-2463.

41. Elkoby, R., "Full-Scale Propulsion Airframe Aeroacoustics Investigation,” AIAA paper 2005-2807. 